\title{
1 The Pathology of Diffuse Lung Disorders
}

\author{
Charles Kuhn
}

The phrase 'diffuse lung disease' is often used to designate diseases producing bilateral widespread infiltrates in the lung as assessed radiographically or pathologically [1]. A glance at the contents of Part III of this book shows that the term is used herein in a more literal sense to encompass disorders that affect all regions of the lung, whether they primarily involve the airways, the acini or both. This chapter will review the pathologic responses of the conducting airways and gasexchanging parenchyma.

\section{Disorders of the Bronchi}

Conducting airways from the main bronchi down to approximately $2 \mathrm{~mm}$ in diameter have walls reinforced by cartilage and have glands in their walls, the defining characteristics of bronchi. They are lined by a pseudostratified epithelium consisting of ciliated and mucus-secreting columnar epithelial cells and small cuboidal basal cells which are firmly attached to the basal lamina by hemidesmosomes and which provide anchorage for the tall columnar cells. The ciliated cells are post-mitotic, but both the mucous and basal cells have the capacity to divide and differentiate.

After massive inhalation injury such as occurs during fires or chemical disasters, the entire surface epithelium may undergo necrosis. Migration of cells from the ducts of the mucous glands can restore the lining, much as the skin appendages provide the stem cells to repopulate the donor site of a split thickness skin graft. Less severe injury, including many viral infections, destroys the columnar cells, but leaves the majority of basal cells which can spread, multiply and differentiate to restore a complete epithelium. Minimal injury in which only occasional columnar cells are lost can apparently be repaired by division of the secretory epithelial cells with little participation of the basal cells [2].

\section{Chronic Bronchitis}

Chronic or repetitive inhalation of milder irritants produces chronic bronchitis, a condition characterized clinically by cough and sputum production and pathologically by chronic inflammatory infiltration, enlargement of the mucous glands and increased proportion of mucus-secreting cells relative to serous cells. Overwhelmingly, the most common cause of chronic bronchitis is tobacco smoke, which doubtlessly accounts for the association of chronic bronchitis with chronic airflow obstruction (chronic obstructive pulmonary disease, COPD). It was shown more than 25 years ago that the major increase in airflow resistance in COPD occurs in airways less than $2 \mathrm{~mm}$ in diameter [3]. Many subsequent studies have shown closer correlations of physiological measures of airflow obstruction to bronchiolar pathology and emphysema than to measures of mucous gland hypertrophy. Consequently, chronic bronchitis, which occurs in nearly all heavy smokers is unlikely to be a causative factor in COPD which occurs in only $10 \%-20 \%$ of smokers. 


\section{Asthma}

The pathology of asthma has long been known from autopsies of patients dying in status asthmatics. Biopsies of non-fatal asthma show qualitatively similar changes, differing mainly in their lesser severity [4]. The pathologic changes are complex and the airway hyperreactivity characteristic of asthma is best regarded as multifactorial.

One striking feature of the macroscopic appearance of an asthmatic lung is the abundant mucus plugging the airways. Microscopically, the plugs contain fibrin and cells as well as mucus. Conspicuous exfoliation of epithelial cells and influx of eosinophils are characteristic. The CharcotLeyden crystals typical of asthmatic sputum result from the release of a poorly soluble lysophospholipase from degenerating eosinophils.

The surface epithelium lining the bronchi in asthma shows an increased proportion of mucussecreting goblet cells and varying degrees of damage. Mild epithelial damage is manifested mainly in the ciliated cells and consists of non-specific signs of cell injury such as swelling and disruption of organelles and damage and loss cilia [5]. Severe damage leads to sloughing of the columnar cells, usually leaving the less vulnerable basal cells behind (Figure 1.1a). These epithelial changes may contribute to hyperreactivity of the airways to inhaled stimuli by opening up the barrier which normally protects the intramucosal mast cells and the tachykinin-containing intramucosal sensory nerves [6]. They also contribute to the impaired mucociliary clearance characteristic of asthma.

A conspicuous morphologic feature of bronchial mucosa in asthma is the presence of marked thickening of a glassy eosinophilic layer of densely packed interstitial collagen fibres which lies just beneath the basal lamina and is called the reticular zone. This characteristic morphologic change is not specific, and the range of thickness seen in asthmatics overlaps that seen in other forms of bronchitis.

The walls of the bronchi in asthma are markedly thickened as shown by both morphometry and high resolution computed tomography (CT). Many components contribute to this thickening, including edema and infiltration of inflammatory cells in the lamina propria, dilation of blood vessels, hypertrophy of mucous glands. Hypertrophy of the smooth muscle is a well documented finding in fatal asthma [7], although it was not found in one autopsy study of asthmatics dying of other causes [8].

The infiltration of inflammatory cells is an important part of asthma, possibly contributing to the hyperreactivity of the airways directly, or indirectly by causing damage to the epithelium. Eosinophils greatly outnumber neutrophils [9]. They are implicated in the epithelial injury because their products such as major basic protein, eosinophil cationic protein and neurotoxin are toxic to cultured bronchial epithelial cells and are demonstrable extracellularly by immunohistochemistry in proximity to sites of damage to airway epithelium. The recruitment of eosinophils in allergic asthmatics may be brought about in part by activation of mast cells by specific antigens. Another set of signals to recruit eosinophils comes via the products of helper T-lymphocytes of the TH2 subset [10]. These cells cannot be distinguished from the other lymphocytes in tissue sections; their presence is deduced from the presence of their characteristic cytokines, interleukin-4 and interleukin-5, and the absence of gamma interferon, the characteristic cytokine of the TH1 subset of helper T-cells, those that participate in delayed type hypersensitivity reactions.

The rapidity of the response of hyperreactive airways to inhaled stimuli suggests the involvement of autonomic reflexes. One source of neurotransmitters is the intraepithelial sensory C-fibres [11] which become sensitized as a result of the damage to the epithelial cells and their junctions and which release tachykins in the vicinity of the mucous glands and smooth muscle via axon reflexes.

An imbalance between the bronchoconstrictor and secretagogue cholinergic nerves and the inhibitory peptidergic and nitrergic nerves has been suggested by studies showing diminished vasoactive intestinal peptide-containing nerves in asthmatic airways, but others have failed to confirm the observation.

The epithelium of the membranous bronchioles is relatively spared in asthma, but in chronic cases, thickening of the lamina propria of the bronchioles has been documented by morphometry [12] (Figure 1.1b). As the smooth muscle shortens during bronchoconstriction, the connective tissue of the lamina propria is thrown into folds which project into the lumen. Computer simulations indicate that the thickening of the lamina propria would cause little change in airflow resistence when the bronchioles are relaxed. During bronchioloconstriction, however, the infolding of the thickened asthmatic lamina propria rapidly narrows the airway lumen causing a precipitous rise in resistance, much greater than that produced by a similar degree of smooth muscle shortening by normal bronchioles [13]. Hence, the structural remodelling in the small airways may also contribute to the airway hyperreactivity in asthma. 

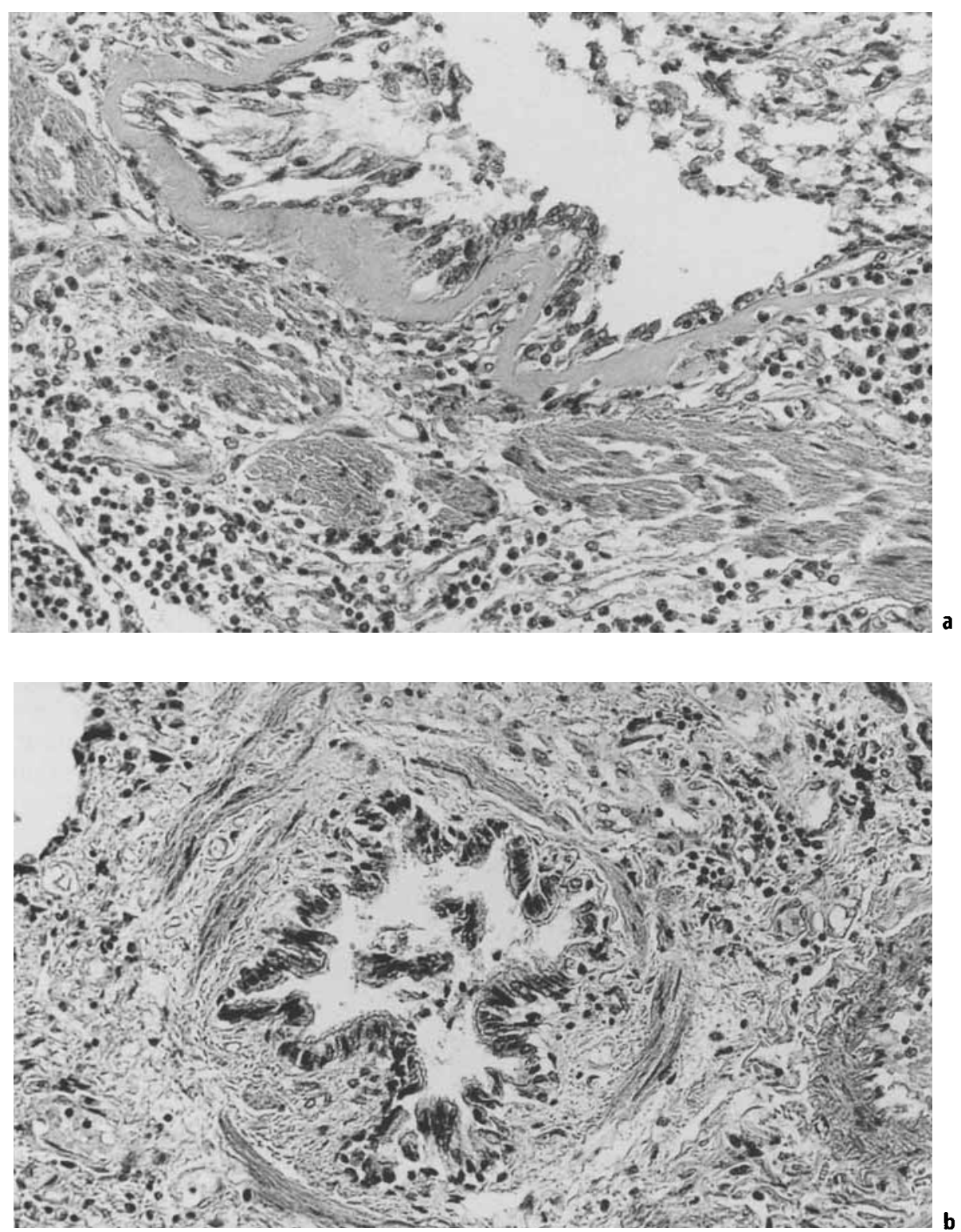

Figure $1.1 \mathrm{a}, \mathrm{b}$. Asthma, a Large airway. The lumen contains a mixture of mucus and sloughed columnar epithelium. The residual attached epithelial cells are mainly basal cells. The reticular layer is markedly thickened. Smooth muscle is hypertrophied and the bronchial wall heavily infiltrated with inflammatory cells. Hematoxylin-eosin stain. b Bronchiole in asthma. Same patient as in a. There is substantial thickening of the lamina propria separating the smooth muscle from the lining epithelium.

\section{Bronchiectasis}

In bronchiectasis, the normal gradual taper of successive generations of bronchi is lost and they remain dilated out to the periphery of the lung. The configuration of the dilated bronchi may be cylindrical or saccular and varicose. For the most part, the walls of the dilated bronchi are markedly thick- ened and inflamed; but the saccular segments may be thinned as a result of destruction of the normal components of their walls including much of the cartilage and the elastic fibres and smooth muscle which normally provide inward tension resisting the outward tension of the surrounding fibrotic alveolar walls. The normal components of the bronchial wall are replaced by chronic inflammatory tissue and 
fibrosis. Often in bronchiectasis a massive infiltration of lymphocytes occurs with the formation of follicles with germinal centres. In this case pathologists may use descriptive diagnoses such as follicular bronchiectasis or follicular bronchitis. The bronchioles distal to bronchiectasis are often inflamed or obliterated and the surrounding lung fibrotic [14].

Bronchiectasis follows severe inflammatory injury to the bronchial wall [15]. The cause is usually infection, but bronchiectasis may also be initiated by chemical injury (i.e., aspiration of gastric acid or inhalation of ammonia) or by immunologic processes such as rheumatoid arthritis or allergic bronchopulmonary aspergillosis in which infection of bronchial wall is not thought to occur. Bronchiectasis is typically a localized process, developing in sites of prior pneumonia or distal to a site of obstruction. Widespread disease develops in the presence of generalized dysfunction of antibacterial systems, notably in hypoglobulinemia, in primary ciliary dyskinesia, and in cystic fibrosis. Primary ciliary dyskinesia is autosomal recessive hereditary condition in which the normal metachronal coordinated beating of the cilia is impaired. Cilia may be completely paralyzed or have slow desultory vibrations which are ineffective at propelling the mucous blanket. A variety of underlying abnormalities have been described by electron microscopy, the commonest being absence of either or both of the two rows of dynein arms, structures visible only by electron microscopy which power ciliary beating by hydrolyzing ATP [16] (Figure 1.2). As a result of the defect, mucociliary clearance is markedly prolonged and airway mucus is removed by coughing. Afflicted patients suffer from sinusitis, nasal polyps, recur- rent otitis, and frequent chest infections beginning early in life. Men are usually sterile owing to involvement of sperm flagellae. In $50 \%$ of patients there is dextrocardia or situs inversus and the diagnosis of Kartagener's triad is appropriate. Despite similarities to the respiratory manifestations of cystic fibrosis, the course of primary ciliary dyskinesia is comparatively benign.

Cystic fibrosis is an autosomal recessive disease caused by the inheritance of two mutant alleles of the gene CFTR (cystic fibrosis transmembrane conductance regulator) located on the long arm of chromosome 7 [17]. This gene encodes an integral membrane protein which is itself a chloride channel, but has additional functions in regulating other membrane channels involved in sodium and chloride transport [18-20]. Although more than 450 different mutations in CFTR have been described, $70 \%$ of the abnormal alleles in Caucasians result from a single mutation, deletion of the codon for phenylalanine at position 408 . This deletion causes misfolding of the protein, which is then tagged and degraded by a cellular quality control system, so that little of the protein is present in the membranes of affected cells [21]. Several other mutations cause dysfunctional protein to be present in normal amounts [17].

The consequences of inadequate function of CFTR in the lung are complex: there is excessive unregulated sodium transport away from the airway lumen which may lead to dehydration of the mucus and impaired mucociliary clearance. Paradoxically, the concentration of salt in the airway lining fluid may be abnormally high, inhibiting beta-defensin, a broad spectrum antimicrobial peptide secreted by airway epithelial cells $[22,23]$. Dysfunctional
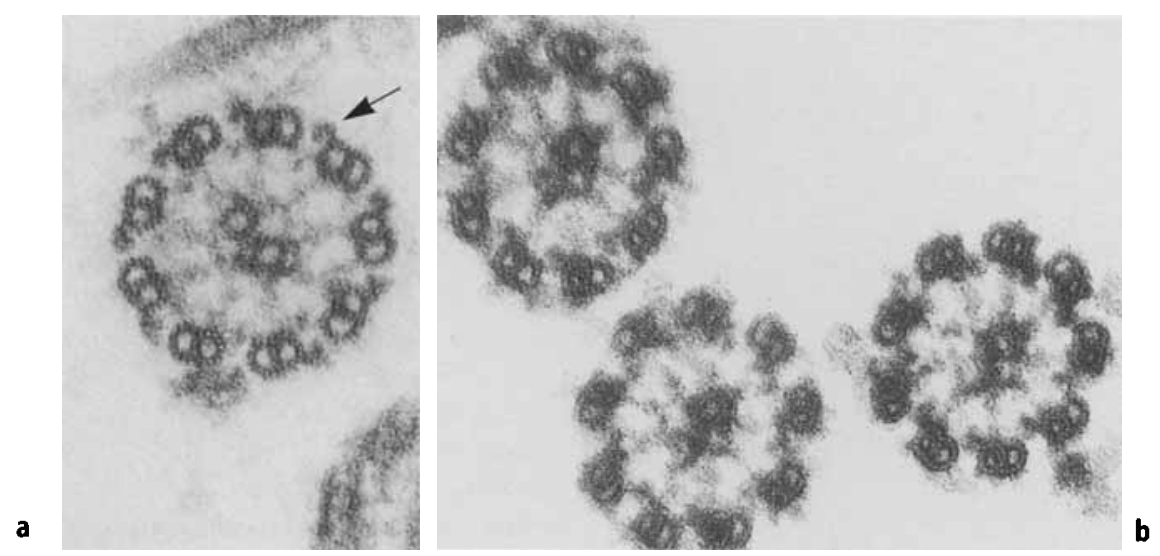

Figure $1.2 \mathrm{a}, \mathrm{b}$. Electron micrograph of ciliary axonemes, the functional structure of the cilia, after removal of the plasma membrane. a Normal with outer dynein arms (arrow) visible. b Primary ciliary dyskinesia with outer dynein arms absent. 
CFTR may also lead to abnormalities in the glycosylation of epithelial cell surface molecules favoring colonization by particular pathogens including Pseudomonas $[24,25]$. Once colonization is established it triggers inflammatory reactions that recruit neutrophils to the airway [26], damaging the epithelium, and augmenting the viscosity of the mucus by the addition of DNA molecules and cytoskeletal filaments released from the degenerating neutrophils [17]. This leads to a self-perpetuating process in the bronchial wall with infection, bronchiectasis and repeated bouts of pneumonia.

Bronchiectasis can accompany long-standing asthma, especially when allergic bronchopulmonary aspergillosis (ABPA) is present. ABPA is a syndrome caused by allergy to antigens from colonizing non-invasive Aspergillus and manifest by blood eosinophilia, high titers of IgE antibodies to Aspergillus antigen, bronchiectasis, and peripheral lung infiltrates. Total IgE is usually markedly elevated and skin tests to Aspergillus antigen are positive but neither of these tests is as useful diagnostically as the specific $\operatorname{IgE}$ antibody against Aspergillus [27].

In typical examples of ABPA, the bronchiectasis involves the proximal airway generations, segmental and subsegmental, while the more peripheral airways are patent and taper normally. Mucoid impaction of the bronchi is common. Microscopic examination of impacted bronchial plugs that have been expectorated or extracted through a bronchoscope shows numerous eosinophils, Charcot-Leyden crystals, and often fungal hyphae. The peripheral infiltrates seen radiographically have a varied histology. They may show eosinophilic pneumonia, obstructive pneumonia, granulomas or fibrosis. A distinctive microscopic lesion which is often associated with ABPA, but which also has other causes, is called bronchocentric granulomatosis. In bronchocentric granulomatosis, bronchioles become inflamed, the epithelium is replaced by palisading epithelioid cells and the former bronchial lumen is filled with either necrotic material or an exudate which may be composed of neutrophils or eosinophils. Special stains show fungal hyphae in most cases $[28,29]$.

\section{The Bronchioles}

The structure of the final few generations of conducting airways differs from that of more proximal bronchi. The epithelial lining is composed of two principal cell types, ciliated cells and non-ciliated secretory (Clara) cells. Basal cells are few. The wall is composed of a thin lamina propria and bundles of smooth muscle. Lacking the rigidity provided to the proximal airways by their cartilage, the caliber of the bronchioles is influenced by the inward tension of surface forces in their lining fluid and the outward tension provided by the elastic recoil of the surrounding alveolar walls. Consequently, disease in the surrounding tissue influences the function of the bronchioles.

\section{Bronchioles in Chronic Airflow Obstruction of Smokers}

It is accepted that the major increase in resistance to expiratory flow in COPD of cigarette smokers occurs in small airways [3]. The morphologic changes there are surprisingly subtle [30,31]. Indeed, one authority reviewing his own 25 years of study along with the work of others admitted that we still do not understand the pathologic changes in the bronchioles that provide the basis of COPD [32]. Among the relevant changes, metaplasia of the epithelium to a mucus-secreting phenotype may interfere with the surfactant function of the normal lining fluid. Inflammation in the bronchiolar walls, another correlate of COPD, may compound the effect of the mucous metaplasia by causing exudation of fibrin, an established surfactant inhibitor. Inflammation also may alter the reactivity of the smooth muscle, lead to fibrosis of the airway walls, and contribute to the destruction of the surrounding alveolar walls. Narrowing and tortuosity of the lumen of the bronchioles are demonstrable by radiography, corrosion casts, and histologic techniques. They are the combined effect of intramural fibrosis and changes in the surrounding parenchyma including loss of alveolar attachments, loss of elastic recoil and emphysematous destruction.

Some of the discrepant data in the literature can be explained if bronchiolar inflammation is more important in mild COPD and emphysema in fatal COPD [33]. The two are difficult to dissociate, however. It has long been recognized that bronchitis and bronchiolar inflammation commonly accompany the centriacinar type of emphysema. But even the panacinar emphysema of the alpha-1-antitrypsin deficiency is accompanied by bronchitis at autopsy and epidemiologic observations associate asthma with predisposition to COPD in those with the Pi $Z$ antitrypsin phenotype [34]. 


\section{Bronchiolitis Unassociated with Smoking}

Inflammation of the bronchioles is a common accompaniment of viral infections. In very young children whose bronchioles are small and whose collateral ventilation is poorly developed, viral bronchiolitis produces a characteristic clinical syndrome dominated by signs of marked acute airflow obstruction. Its usual cause is respiratory syncytial virus, but other organisms including influenza, parainfluenza, adenovirus and Mycoplasma pneumoniae can cause a similar syndrome. In viral bronchiolitis, the walls of the bronchioles are thickened by an intense infiltration of mononuclear inflammatory cells. The bronchiolar epithelium may show degeneration, sloughing, or overt necrosis depending on the organism and severity of infection. An acute exudate of degenerating neutrophils and monocytes is often present in the lumen. Intranuclear inclusions are present in adenoviral bronchiolitis, but culture or immunologic techniques are needed to diagnose most other etiologies. An accompanying bronchopneumonia may be present. Healing of the more destructive cases of bronchiolitis can lead to chronic sequellae such as bronchiectasis, obliterative bronchiolitis, and unilateral lung transradiancy [15]. Epidemiologic and molecular evidence suggests that less severe bronchiolitis in childhood may predispose to COPD many years later [35].

Among the non-infectious causes of bronchiolitis are certain toxic inhalents, collagen-vascular disease especially rheumatoid disease and Sjögren's syndrome, transplant-related obliterative bronchiolitis, mineral dust-induced bronchiolitis, and diffuse pan-bronchiolitis $[30,36]$. Inevitably, for some patients the cause is unknown [37].

Several morphologic patterns of bronchiolitis are recognized by pathologists (Figure 1.3). In lymphocytic bronchitis and bronchiolitis an intense lymphocytic inflammatory infiltrate sometimes with formation of germinal centers affects airways of various sizes [38]. This pattern is seen in rheumatoid disease and Sjögren's syndrome (Figure 1.3a). Scarring of the bronchioles can produce irreversible airflow obstruction. The healing of intramural inflammation and the organization of intraluminal exudate produce two different morphologic pat- terns of fibrosis described as constrictive bronchiolitis [37] and obliterative bronchiolitis with intraluminal polyps (Figure 1.3). The obliterative pattern predominates with relatively severe injury to the epithelium such as with toxic inhalents, viruses and the bronchiolitis seen in graft-versus host disease and in transplanted lungs. The fibrosis is the result of the organization of exudate within the bronchial lumen and may take the form of a polypoid collection of fibroblasts and extracellular matrix protruding into the lumen of the bronchiole, or may completely fill the lumen. In the constrictive form, the lumen is narrowed by concentric fibrosis between the epithelium and the smooth muscle. In addition smooth muscle hyperplasia and adventitial fibrosis are common [39].

Diffuse panbronchiolitis is a chronic progressive disease that is rare outside of Asia. It is a chronic inflammation beginning in the respiratory bronchioles and spreading proximally to the membranous bronchioles and eventually to the central bronchi which become bronchiectatic late in its course. The microscopic changes are an intense lymphocytic and plasmacytic infiltration of the walls of the respiratory and membranous bronchioles accompanied by intraluminal and interstitial foamy macrophages $[40,41]$.

The clinical consequences of bronchiolitis include airflow obstruction, dyspnea, and hypoxemia when there is poor matching of ventilation to perfusion. Radiographs may show fine nodules particularly when bronchiolar walls are thickened by cellular infiltrates. When the disease progresses to scarring, the airways may not be visible but diagnosis can be suspected when there are patchy areas of hyperlucency that are exaggerated during expiration [42].

\section{The Acinar Region of the Lung}

The membranous bronchioles continue distally for several generations until they gradually change into gas exchanging tissue. An acinus is the term used for the unit of lung supplied by a terminal bronchiole. It contains the functional elements participating in gas exchange which are the respiratory

Figure 1.3 a-c. Types of bronchiolitis. a Cellular bronchiolitis in Sjögren's syndrome. b Proliferative bronchiolitis. There is a polyp of connective tissue protruding into the lumen $\left(^{*}\right)$. Note the flattened regenerating epithelium over the surface of the polyp. c Constrictive bronchiolitis; concentric fibrous thickening of the lamina propria beneath the smooth muscle. 

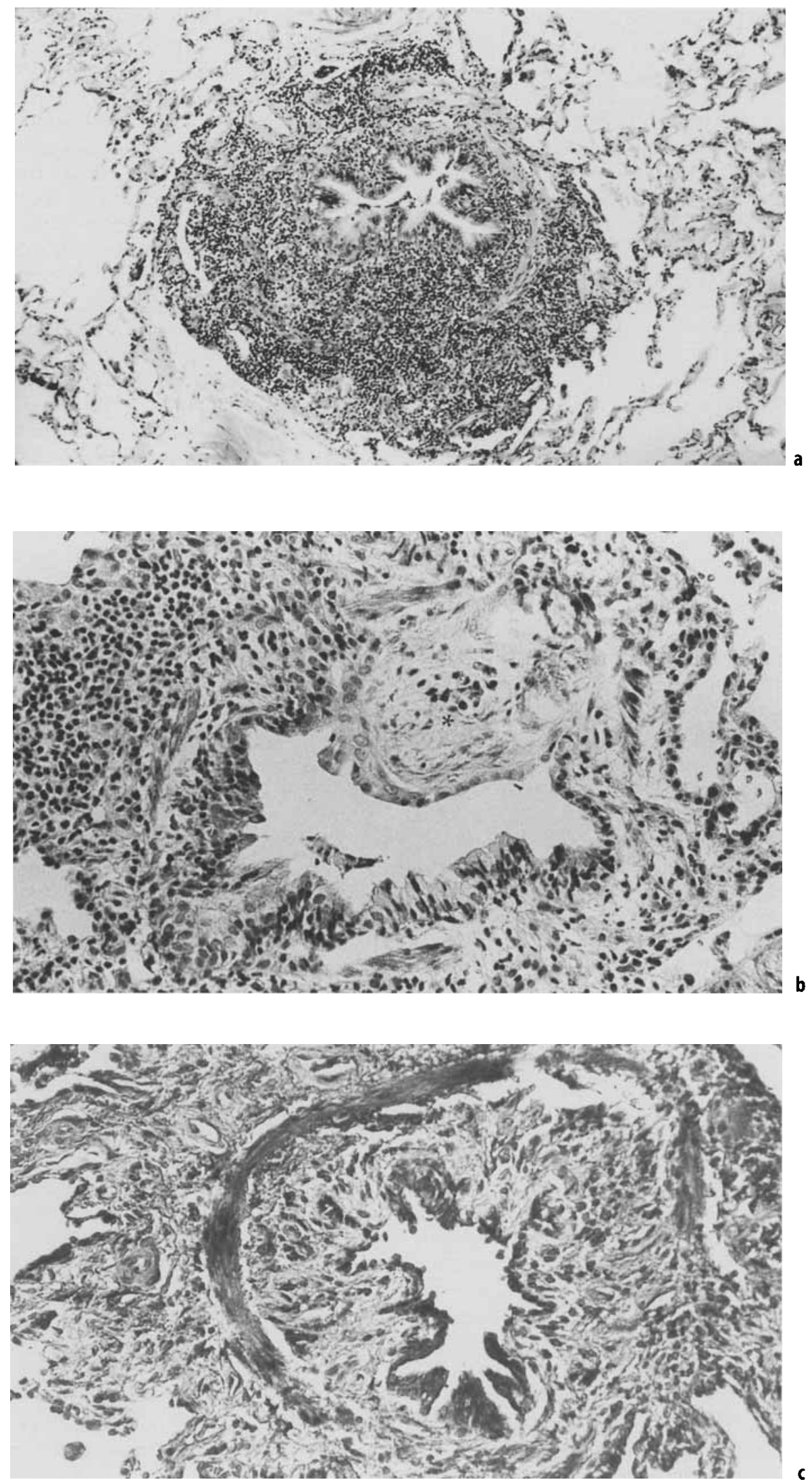
bronchioles partly lined by bronchiolar epithelium and partly by alveoli and the alveolar ducts and sacs entirely composed of alveoli. The alveoli are formed by a dense network of capillaries reinforced by a small interstitial compartment containing connective tissue cells and fibers and covered by an epithelium composed of two types of cell. The type I or squamous epithelial cells sends a very thin sheet of cytoplasm only 0.2 microns thick to cover the capillaries and form the blood-air barriers. The type II cell is a cuboidal secretory cell that produces surfactant. Although there are two type II cells for every type I cell, $98 \%$ of the alveolar surface is covered by type I cell cytoplasm and the surface to volume ratio of the type I cell is 25 times that of the type II cell. It is not surprising therefore that the type I cell bears the brunt of most types of lung injury. The more compact and metabolically active type II cell is the reparative cell in the response to alveolar injury.

\section{Emphysema}

The alveolar ducts and sacs are reinforced by thick bands of collagen and elastic fibers which wind down the duct in a spiral connected to rings of similar fibers at the mouths of alveoli. The inward tension of this connective tissue network balances the outward forces of surface tension in the alveolar lining and tension in the small fibers of the alveolar interstitium. The balance provides a stable structure [43].

Over many years there is a very gradual loss of elasticity in the fiber bundles in the ducts. As a result, the ducts tend to dilate and the alveoli become shallower. This structural change is associated with a gradual loss of elastic recoil measured physiologically, as well as a minor but steady decline in $\mathrm{FEV}_{1}[44]$. Because these changes are universal, they are not considered to be emphysema, which is defined as an abnormal permanent increase in the size of airspaces accompanied by destruction of their walls and without obvious fibrosis [45].

In a normal lung the alveoli are invisible and the alveolar ducts are just at the limit of resolution by the unaided eye. In emphysema the air spaces are enlarged to an extent that they become easily visible to the unaided eye, but with the qualification that the lung is not fibrotic because with fibrosis, honeycombing also produces macroscopic holes in the lung but has an entirely different clinical physiology than emphysema.
Traditionally, pathologists classify emphysema according to the portion of the acinus involved [33]. Emphysema involving mainly the respiratory bronchioles is termed centriacinar. It shows an upper zone predominance and is strongly associated with smoking and airways disease. It has a characteristic macroscopic appearance because the emphysematous holes, being located initially in respiratory bronchioles, are surrounded by the uninvolved alveolar ducts and sacs adjacent to the pleura and perilobular septa (Figure 1.4). The other major clinical form of emphysema, panacinar, involves alveolar ducts and sacs throughout the acinus. It has a more uniform distribution across the lung from apex to base but can show accentuation in the lower lung fields. It is the characteristic type of emphysema associated with alpha-1-antitrypsin deficiency, but is also associated with smoking. It appears macroscopically as a coarsening of lung architecture with easily visible airspaces throughout lobules including the tissue adjacent to septa and pleura (Figure 1.5).

Limitations of this classification stem from the fact that mixed forms of emphysema are common and that in advanced emphysema the two may not be distinguishable. A third type, distal acinar emphysema, in which holes in the parenchyma abut the perilobular septa and pleura, is more important clinically as a cause of pneumothorax than of COPD.

Minor degrees of emphysema are common in pathologic specimens and cause no clinical manifestations. Indeed mild pathologic emphysema often could not be diagnosed clinically when the available tools were physiological tests and conventional chest roentgenography. High resolution CT is much more sensitive, although even this technique may under-diagnose emphysema.

When emphysema involves more than $20 \%$ of the lung, clinical manifestations may be present. The correlation between spirometic measures of airflow obstruction and extent of emphysema is not very close, presumably because intrinsic bronchiolar lesions also influence these tests. Some have also suggested that alterations in the parenchyma between the emphysematous holes influence the mechanical behavior of the tissue more than the holes themselves [32]. The test giving the best correlation with extent of emphysema measured either pathologically or by computed tomography is the diffusing capacity, presumably because it provides a direct measure of loss of capillary volume which is a manifestation of emphysematous lung destruction. The airflow obstruction relates to two manifestations of the diminished elastic recoil of emphysematous lung; (1) diminished driving force for expiratory 


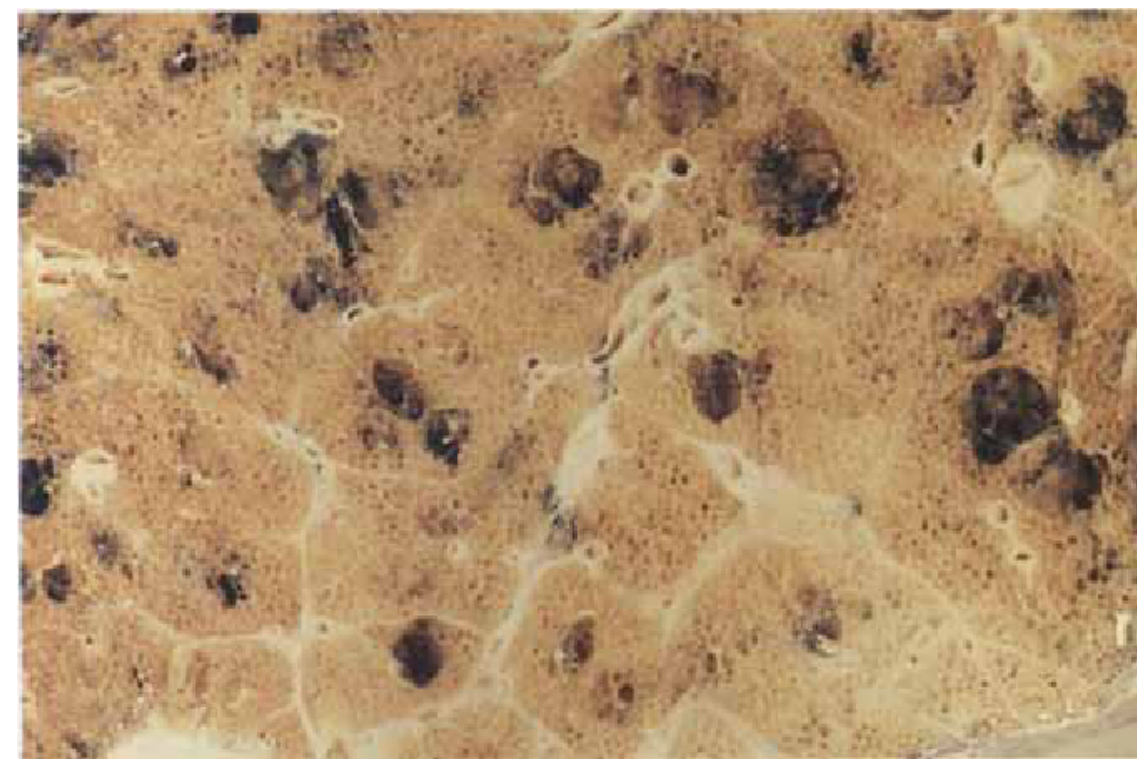

Figure 1.4. Centriacinar emphysema. The emphysematous spaces are separated from the perilobular septa by normal parenchyma.

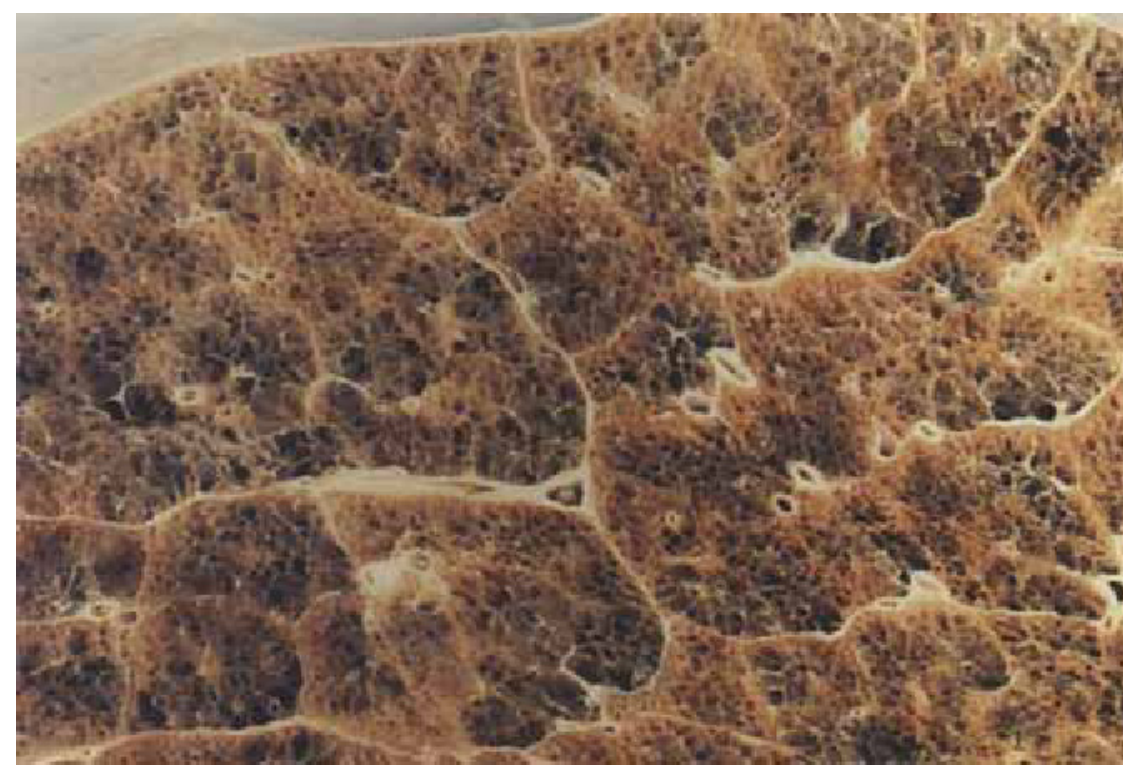

Figure 1.5. Panacinar emphysema. Abnormally enlarged air spaces are present throughout the lobules and abut the perilobular septa.

flow and (2) diminished support of small airways by the surrounding abnormally compliant parenchyma leading to airway closure.

The pathogenesis of emphysema is triggered by degradation of lung connective tissue by enzymes released by inflammatory cells $[46,47]$. In the case of the emphysema associated with alpha-1-antitrypsin deficiency this degradation is caused by un- opposed activity of neutrophil elastase, the main target of alpha-1-antitrypsin $[48,49]$. In the usual case of the smoker with genetically normal antitrypsin, several enzymes active against connective tissue have been implicated in recent studies $[50,51]$. There is also evidence that tobacco smoke oxidatively inactivates antitrypsin, but some investigators have failed to confirm this phenomenon [52]. 


\section{Diffuse Infiltrative Lung Diseases}

Disorders of the acinar region of the lung can be classified according to their distribution within the acinus and according to patterns of histologic response. Both give diagnostic and pathogenetic information. Bronchiolocentric processes are generally the result of inhaled agents and include airborne infections, particulate aspiration, hypersensitivity pneumonia, pneumoconiosis and tobacco-related diseases such as respiratory bronchiolitis, centriacinar emphysema, and possibly Langerhans cell granulomatosis (eosinophilic granuloma). Blood-borne diseases tend to favor the lower lung fields and to be random within the acinus. The lymphatics of the acinus ramify in the loose connective tissue of the bronchovascular bundles, pluera and perilobular septa, but are entirely lacking in alveolar walls. Diseases that favor a lymphatic distribution include malignant lymphomas, lymphangiatic metastases and some cases of sarcoidosis. Relatively few diseases are purely interstitial or purely alveolar at a microscopic level. Examples of the former include uncommon pure proliferations of interstitial cell types such as lymphangioleiomyomatosis and early stages of some metabolic processes such as metastatic calcification or septal amyloidosis. Alveolar filling occurs in hemodynamic pulmonary edema, alveolar proteinosis and microlithiasis with only minimal involvement of the interstitium. Inflammatory processes virtually always involve both.

Two major groupings of inflammatory diseases are granulomatous and non-granulomatous [53]. Granulomas are thought to indicate a response to a particulate or poorly diffusable agent and participation of delayed-type hypersensitivity. The nonspecific inflammatory response usually implies injury to the epithelium accompanied by more variable damage to vessels and the interstitial compartment. It implies little about cause, but major morphologic variants correlate with the intensity, chronology and extent of damage. A third major group is proliferative lesions including neoplasms [53].

\section{Non-granulomatous Inflammation}

\section{Acute Lung Injury}

Acute lung injury produces a sterotyped tissue response described as 'diffuse alveolar damage' and a clinical syndrome, the adult respiratory distress syndrome (ARDS). Among the cause of injury are viral infection, aspiration of gastric acid, chemical pneumonia, fat embolism, radiation, drugs, near drowning and systemic inflammatory reactions such as sepsis or acute pancreatitis in which activation of complement, kinins and cytokines trigger leukocyte adhesion in the lung and secretion of damaging oxidants, enzymes, and other mediators. The resultant damage to the closely opposed epithelium and capillaries produces a regular sequence of pathologic changes that is similar irrespective of the initiating cause [54] (Figure 1.6). Initially increased capillary leakage may distend loose connective tissue containing the lymphatics which the clinician can detect as septal lines in the chest radiograph. Soon, the type I epithelium breaks up or sloughs and the alveoli become flooded with edema and fibrin. The edema and fibrin interfere with surfactant function, and the alveoli tend to collapse on the alveolar ducts. After 1-2 days the classic histology develops. The edema persists and the necrotic epithelium and plasma exudate become compacted into hyaline membranes lining alveolar ducts

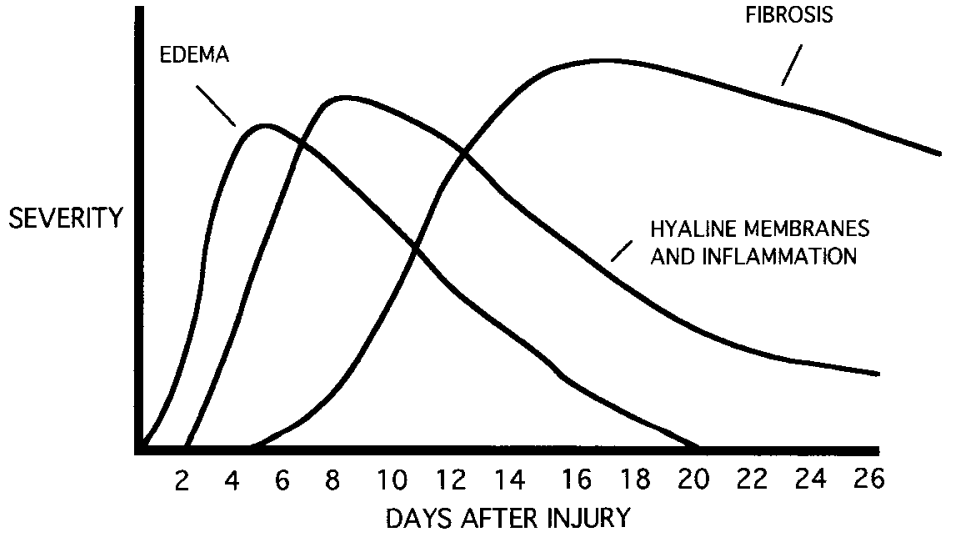

Figure 1.6. Sequence of pathologic changes in diffuse alveolar damage. 
(Figure 1.7). Cellular infiltration varies in extent and composition depending on the etiology, but generally both neutrophils and monocytes are present. By 3-4 days after injury signs of repair can be detected. Type II epithelial cells enlarge, divide and begin to undergo sheet migration to cover tissue denuded by the break-up of the type I cells. If the damage is extensive, by 7-8 days fibroblasts invade persistent exudate within airspaces and progressively replace it with extracellular matrix (Figure 1.8). In as little as 2 weeks, diffuse pulmonary fibrosis can result. Biological factors that influence fibrosis include

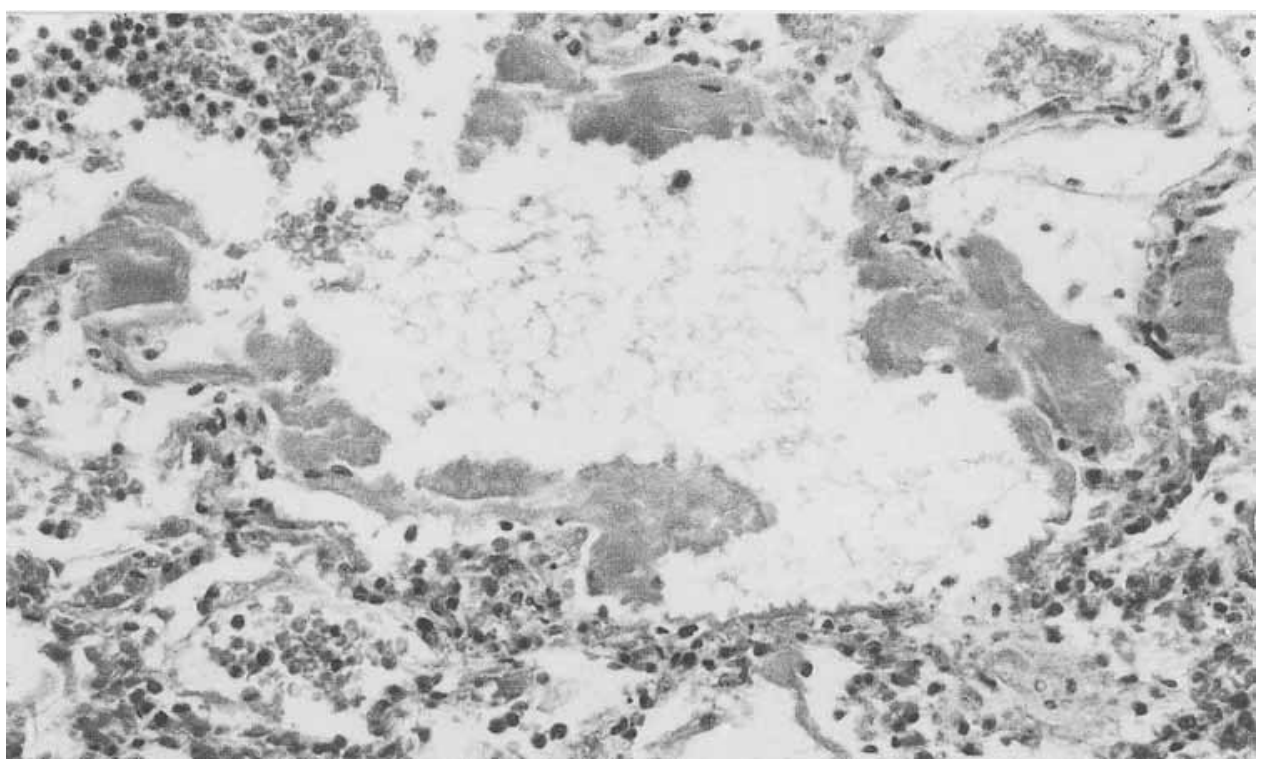

Figure 1.7. Diffuse alveolar damage in the acute phase 3 days after near drowning. An alveolar duct is lined by a hyaline membrane. Predominantly mononuclear inflammatory cells are infiltrating the alveolar walls and some alveolar spaces.

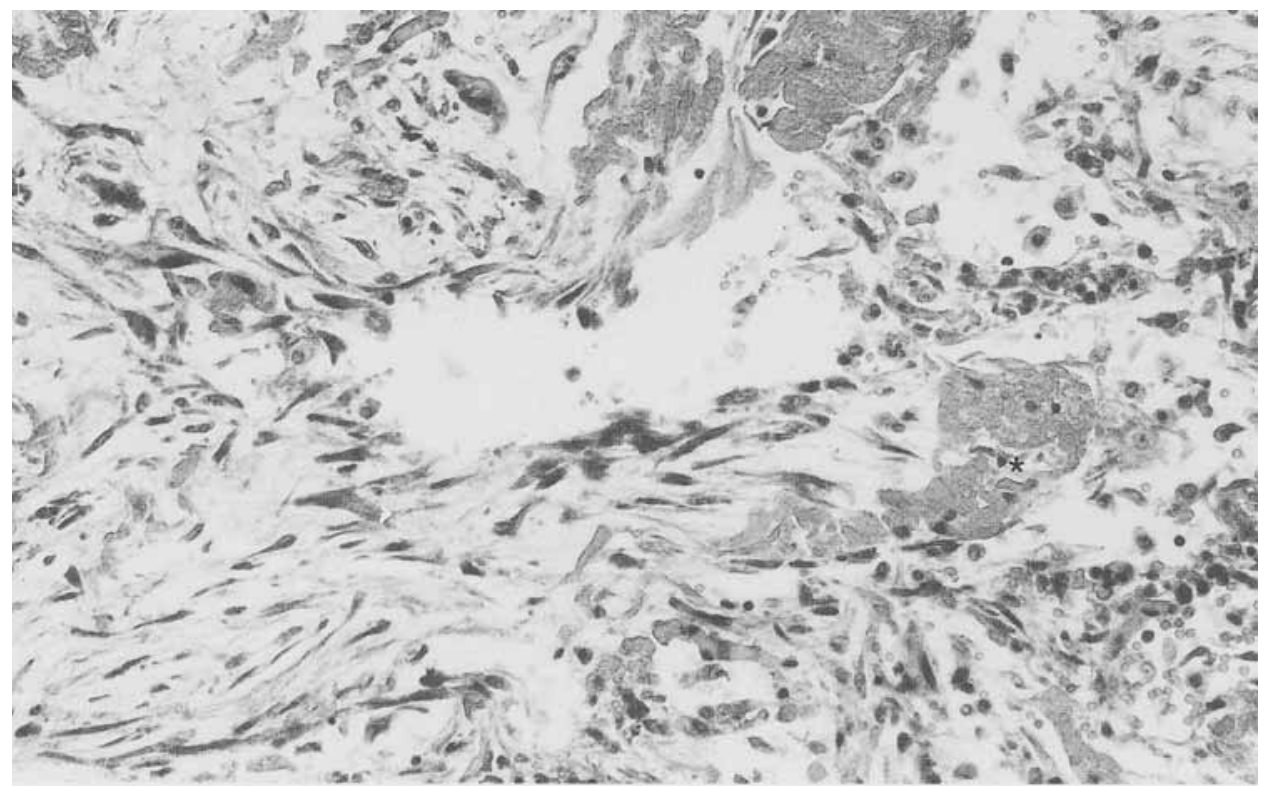

Figure 1.8. Diffuse alveolar damage 8 days following injury. Proliferating fibroblasts are invading and replacing the hyaline membranes, although some remnants of hyaline membrane persist $\left({ }^{*}\right)$. 
extent of basement membrane destruction, the efficacy of the alveolar fibrinolytic system and the efficiency of epithelial repair.

Normal alveoli have fibrinolytic activity generated by the activation of plasminogen by urokinasetype plasminogen activators synthesized by macrophages and type II cells. In the adult respiratory distress syndrome, the fibrinolytic system is inhibited, in part by alpha-2-antiplasmin entering alveoli from the plasma, but mainly because of increased synthesis of an inhibitor of plasminogen activator $[55,56]$. Studies in transgenic and knockout mice have confirmed that the levels of plasminogen activator inhibitor type I, and by extension fibrinolytic activity, are critical determinants of the severity of fibrosis [57].

It has been proposed that inhibition of epithelial regeneration also predisposes to fibrosis. Treatment of experimental animals with a powerful growth factor for type II cells, keratinocyte growth factor, dramatically reduces the fibrosis resulting from the healing of acute lung injury [58].

The clinical course of ARDS varies according to the etiology, but on average the mortality is $50 \%$. Rarely, ARDS seems to arise spontaneously, without identifiable cause, and evolve over a course of a few weeks to fibrosis. To this group the term Hamman-Rich syndrome $[59,60]$ applies. Survivors of ARDS have only minor dysfunction which implies that the lung has a remarkable capacity to repair itself when the underlying lung architecture is not destroyed and that it can remove newly formed connective tissue.

\section{Organizing Pneumonia}

Another non-specific pattern of injury is organizing pneumonia. In most cases this is a process within the acini radiographically and histologically. It causes a reduction in diffusing capacity and restriction of ventilation. Infrequently it may be accompanied by obliterative bronchiolitis affecting non-respiratory bronchioles and only then is the designation bronchiolitis obliterans with organizing pneumonia (BOOP), so popular in the United States, appropriate. Usually the pathologic pattern of organizing pneumonia is seen with disease processes that are less acute than those producing diffuse alveolar damage, and the distribution of lesions is more patchy. Typically the apparent duration of disease is several weeks to several months.

Pathologically, the diagnostic feature of organizing pneumonia is the presence of polypoid intraluminal structures called Masson bodies or intraluminal buds (Figure 1.9). These structures are composed of fibroblasts and myofibroblasts within a basophilic extracellular matrix containing rela-

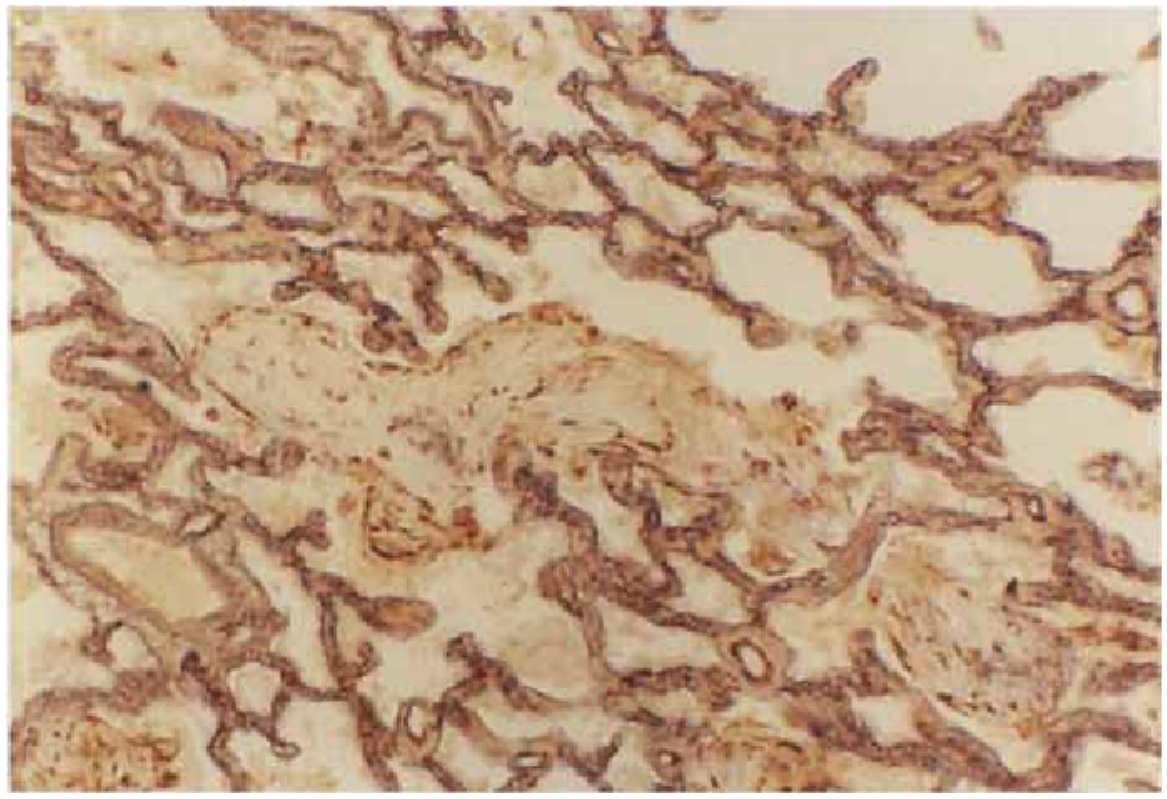

Figure 1.9. Cryptogenic organizing pneumonia. Immunohistochemical stain. Basement membrane collagen stained blue outlines alveolar walls which are only minimally thickened. The brown stain for procollagen type 1 propeptide identifies collagen-synthesizing fibroblasts in Masson bodies in the lumen of alveolar ducts. 
tively sparse collagen fibers in ground substance containing proteoglycans (mainly versican) and glycoproteins (fibronectin, tenascin). Masson bodies arise by the organization of fibrin-rich exudates and usually follow the branching distribution of the respiratory bronchiole alveolar duct system. They may have a few inflammatory cells within them and they gradually become covered with regenerating alveolar epithelium. The walls of the preexisting air spaces may be nearly normal save at the few points of attachment of the Masson bodies, where gaps in the basement membrane are present. More often there is a modest degree of interstitial thickening and inflammation. Collapse of alveoli or accumulation of lipophages are common between and distal to the affected ducts $[61,62]$.

This pattern of tissue response is seen as a sequel to infectious penumonia or following chemical injury, as in smoke inhalation or silofiller's disease (caused by oxides of nitrogen). It can be a manifestation of collagen-vascular disease, drug reaction, or arise spontaneously in patients without evident cause (crytogenic organizing pneumonia). Masson bodies can accompany other types of histologic reactions and are not unusual in hypersensitivity pneumonia, obstructive pneumonia, chronic eosinophilic pneumonia, or during the organizing phase of diffuse alveolar damage.

The most intensely studied form of organizing pneumonia is cryptogenic organizing pneumonia or idiopathic BOOP $[63,64]$. The radiographic distribution of lesions is variable and migratory patchy lobar and segmental consolidations, a multinodular pattern and a bilateral peripheral ('cortical') pattern are recognized. The natural history of the disease is variable [65], but usually improvement can be expected with steroids or even spontaneously.

\section{Chronic Patterns of Reaction}

The original classification of Liebow in the 1960s has been modified and updated by Katzenstein in the light of subsequent knowledge and is a useful way of subdividing diffuse inflammatory reactions that have different prognoses [66]. Idiopathic pulmonary fibrosis or cryptogenic fibrosing alveolitis accounts for $45 \%$ of infiltrative lung disease, making it the most frequent of the chronic diffuse infiltrative lung diseases. Hence, its histologic pattern is termed 'usual' interstitial pneumonia (UIP). Other morphologic patterns that do not follow the typical clinical course of idiopathic pulmonary fibrosis are distinguished by the terms desquamative interstitial pneumonia and non-specific interstitial pneumonia.
The course of idiopathic pulmonary fibrosis is one of gradual deterioration and the morphologic features mirror this natural history.

Two notable features of the pathology of UIP are; (1) the loss of the normal lung architecture in involved tissue with disappearance of many alveoli and much of the vascular bed and (2) an appearance of temporal variability in which burned out areas of scarring, honeycombing and vascular sclerosis coexist with areas of more active inflammation and scattered small foci of active new connective tissue deposition (Figure 1.10). Electron microscopy in UIP shows fresh sites of epithelial necrosis and fibrin exudation even in case of several years duration $[67,68]$. The fibrin exudation may inactivate surfactant, causing microscopic foci of alveolar collapse and provides a matrix for the invasion of fibroblasts. Synthetically active fibroblasts fill alveolar spaces with new connective tissue, prevent reexpansion of collapsed spaces and participate in scar contraction further distorting lung architecture [69-71]. Thus, the morphology indicates a smouldering and continuing inflammatory process gradually destroying the tissue.

Data on the pathogenesis of UIP are fragmentary and contradictory. There are hints that the process may be set in motion by environmental or occupational insults, or by an active or latent viral infection [72,73]. Viral products can activate host genes and trigger cytokine production and the expression of a subset of viral genes could provide antigen for an immune response. The participation of immunologic mechanisms offers an explanation for disease progression and is supported by several observations [74].

Inflammatory infiltrates in UIP consist predominantly of T-lymphocytes accompanied by potential antigen presenting cells, the dendritic cells $[75,76]$. Alveolar epithelium in UIP expresses class II MHC antigens suggesting a capacity to present antigen [77]. In fact, autoantibodies reactive with alveolar epithelium have been found in a high proportion of cases of UIP, but their pathogenic role has not been established $[78,79]$. A variety of cytokines are produced, mainly by macrophages and alveolar epithelial cells, which interact to drive the inflammation and the reparative reactions [80]. Fibroblasts show abnormalities of growth and migration which persist in culture even after the cells are removed from the inflammatory milieu $[81,82]$. It is unknown whether these stable phenotypic abnormalities of the fibroblasts are the result of viral transformation, sustained autocrine-cytokine loops or another, as yet unidentified, mechanism. 

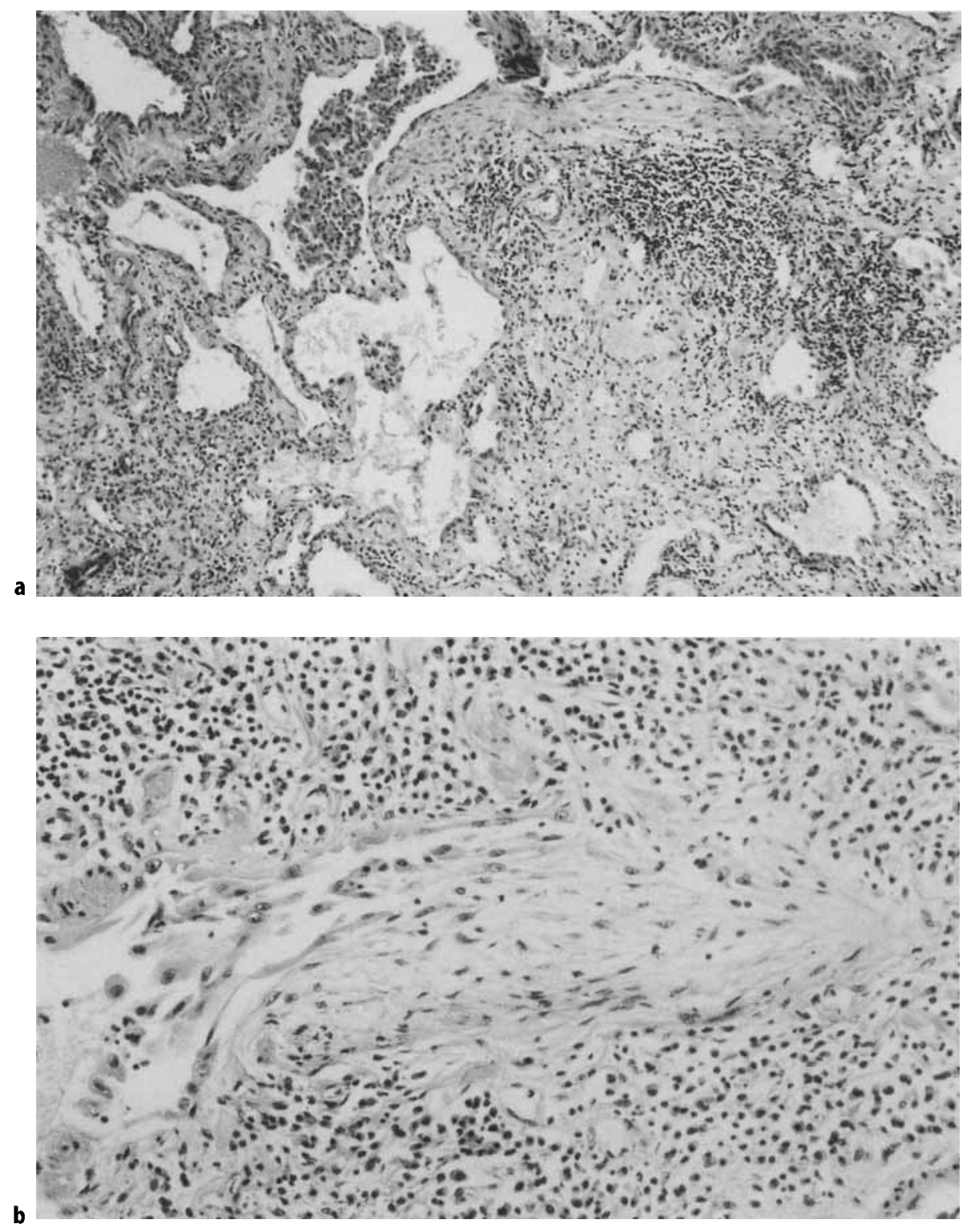

Figure 1.10 a. Usual interstitial pneumonia. At low power there is severe destruction of lung architecture and focally intense inflammation. A focus of active fibroblasts is near the top. $b$ High magnification of another focus of active fibroblasts.

Desquamative interstitial pneumonia is characterized pathologically by retention of lung architecture and extensive filling of air spaces with macrophages (Figure 1.11). The alveolar walls show only mild to moderate thickening mainly by fibrosis and smooth muscle proliferation. The epithelium is hyperplastic and inflammation is mild [83].

Areas within a biopsy from UIP may resemble DIP. In DIP, however, the pattern is uniform. Severe architectural disarray, severe inflammation or foci of active fibroblasts are absent. If these criteria are followed, DIP is often responsive to therapy and follows a much more benign course than UIP [84]. Computed tomography typically shows ground glass attenuation without severe fibrosis or cystic change [85].

There remain cases of chronic infiltrative lung disease that do not meet strict pathologic criteria for UIP or DIP whose biopsies are called nonclassifiable interstitial pneumonia, non-specific interstitial pneumonia or cellular interstitial pneumonia. As a rule, in such biopsies, the basic lung architecture remains intact and all areas show disease of apparently similar age (Figure 1.12). The intersti- 


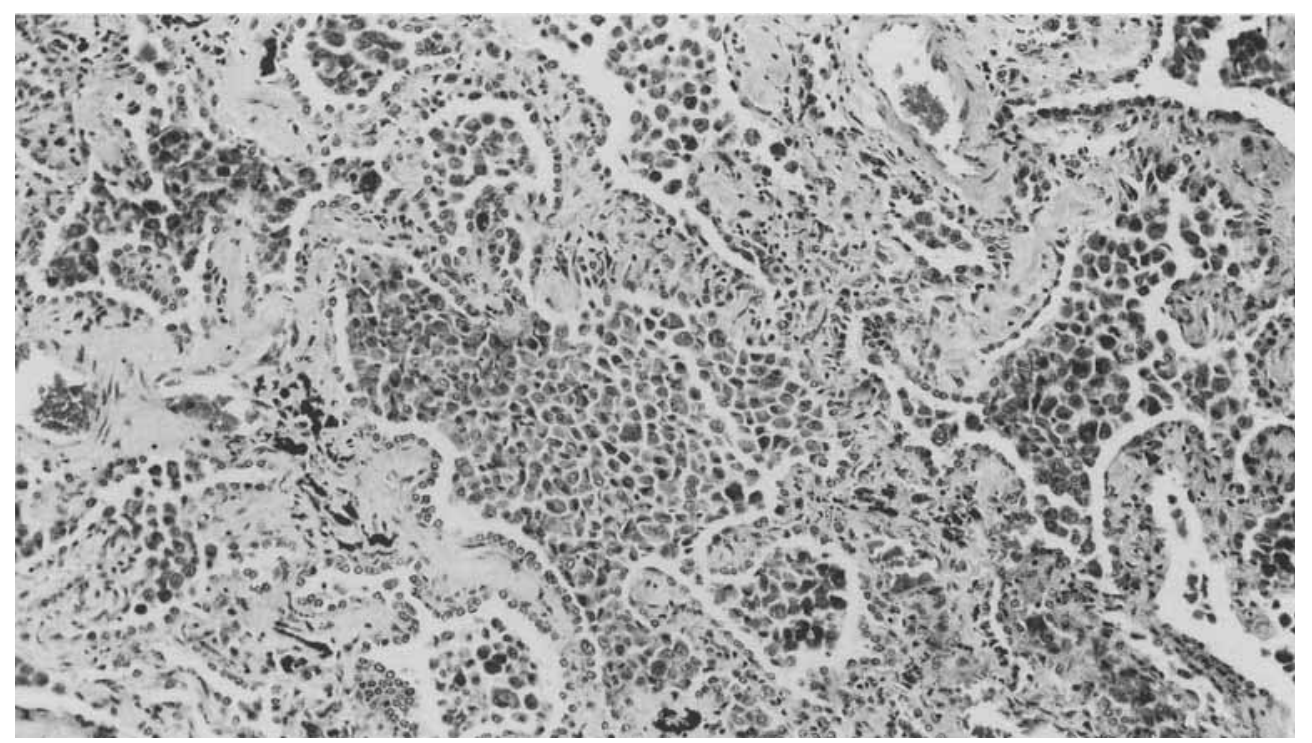

Figure 1.11. Desquamative interstitial pneumonia. Macrophages pack the airspaces. The alveolar septa are mildly fibrotic, but inflammation is mild.

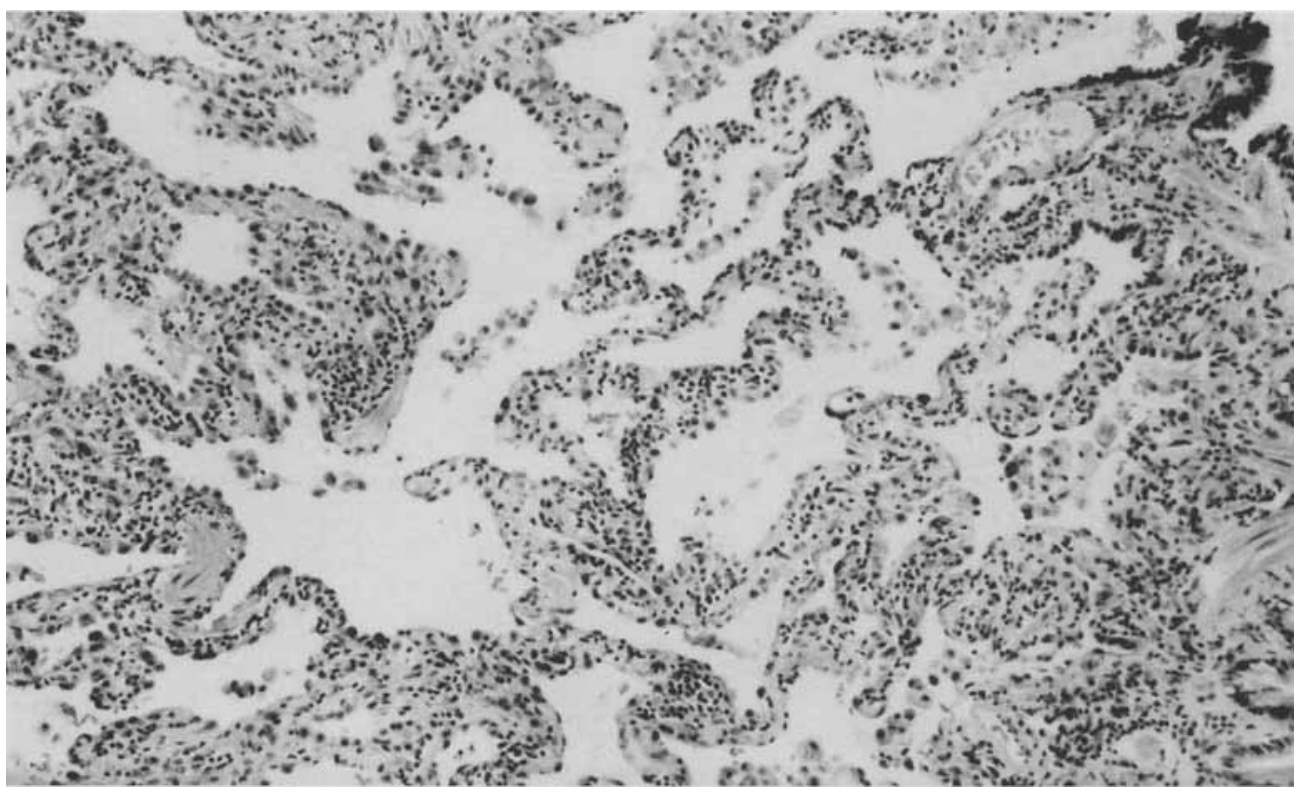

Figure 1.12. Non-specific interstitial pneumonia with relatively uniform inflammatory infiltration of the walls of the air spaces and retention of basic lung architecture.

tium is infiltrated with inflammatory cells but severe fibrosis is seen in only a minority of cases. The alveolar epithelial cells again show reparative hyperplasia and macrophages are increased but not to the degree that they are in DIP. This group of patients is heterogeneous and probably includes cases of hypersensitivity pneumonitis, drug toxicity and collagen-vascular disease as well as an apparently idiopathic group. The importance of distinguishing them from UIP is their considerably better prognosis. The limited follow-up information available indicates a low mortality and potential reversibility except in cases with well established fibrosis [86]. 


\section{Granulomatous Reactions}

Granulomas are of two biological types. Foreign body granulomas are formed by aggregation of ordinary macrophages and multinucleated giant cells around non-antigenic particles with relatively few lymphocytes. The turnover of macrophages is slow and delayed-type hypersensitivity does not develop. Immune-type granulomas are accompanied by delayed-type hypersensitivity and rapid macrophage turnover. They are driven by reciprocal interactions between $\mathrm{T}$-lymphocytes and macrophages. During the waxing phase, the macrophages present antigen to $\mathrm{T}$-helper lymphocytes which in turn secrete cytokines which enhance the microbicidal activity of the macrophages. The formation of epithelioid histiocytes is the morphologic expression of this enhanced microbicidal capacity. If the reaction successfully contains or eliminates the pathogen, the granuloma wanes, aided by the activation of suppressor T-lymphocytes. Among several immunosuppressive cytokines found in waning granulomas is transforming growth factor beta, a powerful fibrogenic signal when it binds to fibroblasts. Thus, fibrosis is a common feature of the healing of granulomas. In severely immunosuppressed patients, such as patients late in the course of AIDS, the macrophages containing intracellular organisms more closely resemble those of a foreign body response than typical epithelioid cells owing to the absence of helper T-cells and their cytokines.

Examples of foreign body granulomas in the lung include aspiration of food particles, inhalation of certain inorganic dusts and intravenous injection of insoluble particles by intravenous drug abusers. The distribution of granulomas reflects the route of deposition. Granulomas from food particle aspiration form nodules localized at the termination of the bronchioles while intravenous drug use produces aggregates of giant cells containing birefringent particles in the lumens and walls of precapillary arterioles.

The classical granulomatous infections such as tuberculosis or fungi most often produce localized lesions but can produce diffuse lung disease. Taking tuberculosis as the prototype, diffuse disease usually arises in one of three ways. In primary tuberculosis, a granuloma in a hilar lymph node typically erodes a central bronchus and discharges organisms from the caseous center into the bronchial tree to cause tuberculous pneumonia. In subapical cavitary reactivation of tuberculosis, liquefaction of the caseous material can lead to dissemination through the airways to cause so-called acinous lesions, granulomatous inflammation fanning out from the terminal bronchioles in the lower portions of the lung. Blood stream dissemination produces randomly distributed miliary nodules which may be caseating or non-caseating granulomas, or even foci of necrosis with few viable macrophages depending on the immune state of the host and dose of organisms.

\section{Sarcoidosis}

In sarcoidosis, the granulomas are well formed and compact (Figure 1.13). Surrounding inflammation is usually not severe, thus the description 'naked tubercles'. A small amount of fibrinoid necrosis in the center of an occasional granuloma is compatible with the diagnosis, but extensive necrosis suggests an infectious etiology. The giant cells may contain inclusions such as asteroid bodies, birefringent crystals, or concentrically laminated calcifications called either conchoid or Schaumann bodies, but none is specific. The granulomas heal by concentric deposition of hyaline connective tissue starting at the periphery of the lesions. Ultimately the granuloma may be replaced, totally converted to a nodule of hyaline connective tissue [87].

All components of the lung can be involved, including airways, blood vessels and the lung parenchyma. Various patterns of lung involvement can occur, but the most characteristic is for the granulomas to be concentrated near the lymphaticcontaining structures, the bronchovascular bundles and perilobular septa. Unlike infectious granulomas, individual granulomas of sarcoidosis do not grow to sizes much above $1 \mathrm{~mm}$, below the level of radiographic detection. Consequently, one often finds granulomas in the lung if transbronchial biopsy is obtained from Stage 1 sarcoidosis patients who have hilar lymph node enlargement but radiographically clear lung fields. Conglomeration of many individual granulomas, often matted together by fibrosis, gives rise to the radiographically visible lesions tracking along the bronchovascular bundles or forming parenchymal nodules.

The etiology of sarcoidosis remains unknown. Some have found evidence for the presence of myobacteria by the polymerase chain reaction or have recovered cell wall-deficient organisms by special cultures but others have failed to repeat these observations [88-93]. The histology is nonspecific and overlaps that of infectious granulomas. Consequently, the diagnosis of sarcoidosis remains a clinical one, combining the clinical picture, the histologic finding of non-caseating granulomas and failure to find an infectious cause by conventional means [94]. 


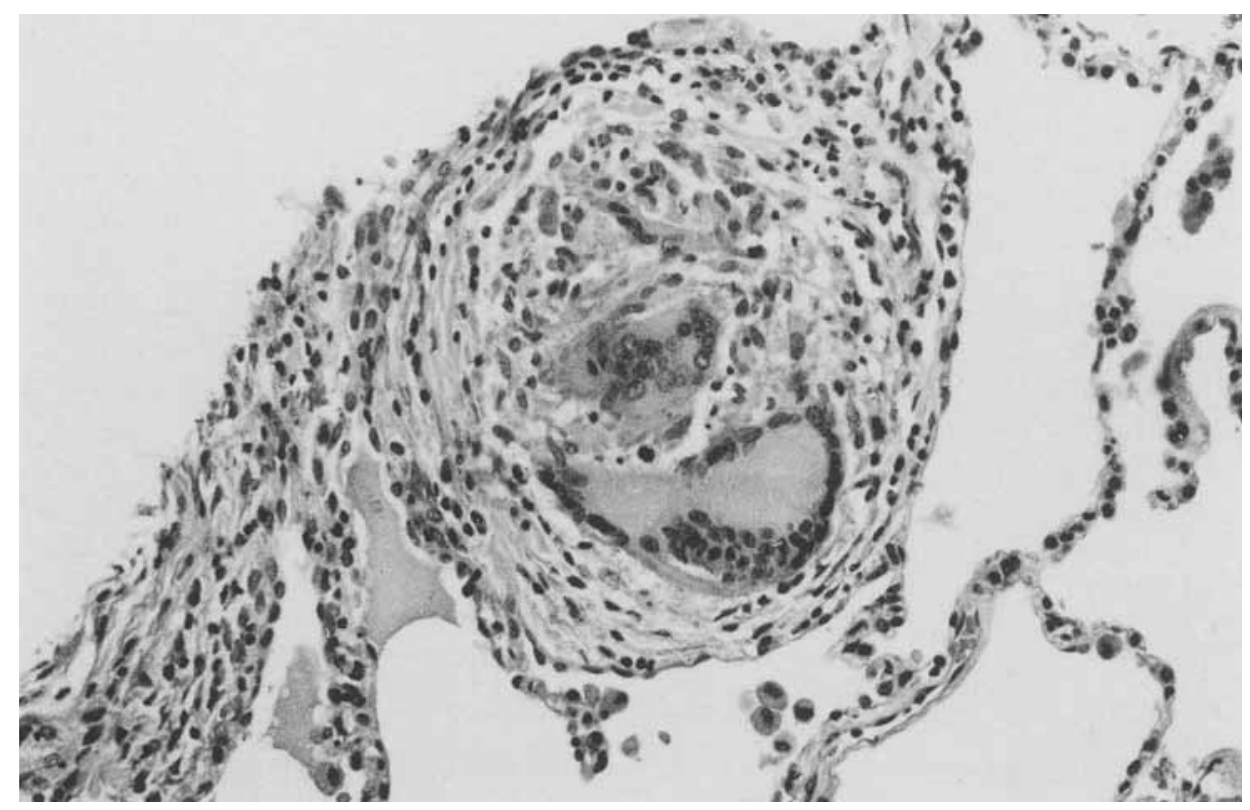

Figure 1.13. Sarcoidosis. A well formed compact granuloma with multinucleated giant cells. Necrosis is absent. A delicate capsule of connective tissue surrounds the granuloma.

\section{Hypersensitivity Pneumonia}

Hypersensitivity pneumonia or extrinsic allergic alveolitis is caused by complex immune reactions to antigenic organic particles such as spores of bacteria or fungi, animal danders, antigens of avian origin and certain synthetic organic chemicals. The immune mechanism may involve a combination of immune complex deposition and cell mediated immunity [95]. A defect in suppressor cell activity may separate reactors from those without disease [96].

The clinical presentation and ease of diagnosis are strongly influenced by antigen dose. When sensitized patients are suddenly exposed to a massive dose of antigen, symptoms develop abruptly after a lag of 4-6 h. It is relatively easy to connect the exposure to the respiratory illness and biopsy is rarely required for diagnosis. Continuous exposure to antigen in the home or workplace leads to a gradual development of chronic infiltrative lung disease which poses a diagnostic challenge [95]. Typically, biopsy shows a patchy bronchiolocentric infiltration of mononuclear inflammatory cells accompanied by loosely formed granulomas composed of macrophages, epithelioid cells and often giant cells of either foreign body or Langhans type [97,98] (Figure 1.14). Organizing exudate in the respiratory bronchioles and alveolar ducts leads to the appearance of Masson bodies similar to those of organizing pneumonia. The full morphologic pattern is diag- nostic, but may not always be present; the distinctive granulomas are only present in approximately $70 \%$ of patients with farmer's lung [97,98]. Late fibrotic disease may be difficult to distinguish from UIP.

A cellular bronchiolitis or bronchiolitis with intraluminal polyps often accompanies the acinar disease of hypersensitivity pneumonia. While restrictive physiology is the rule in hypersensitivity pneumonia, some patients have a mixed obstructive and restrictive pattern, probably reflecting the associated brochiolitis.

\section{Necrotizing Granulomatosis and Vasculitis}

A quite different pattern of granulomatous inflammation is seen in systemic diseases associated with vasculitis. The commonest by far is Wegener's granulomatosis, a systemic disease characterized by necrotizing upper and lower respiratory tract granulomas, vasculitis and glomerulonephritis [99]. Incomplete forms may lack upper or lower respiratory tract involvement or glomerulonephritis [100]. The immunologic mechanisms involved are unclear in many cases. Most immunofluorescent studies of renal biopsies do not support a role for immune complex deposition [101]. The occurrence of antineutrophil cytoplasmic antibodies (ANCA) provides a useful diagnostic test of high but not absolute specificity for vasculitis [102]. 


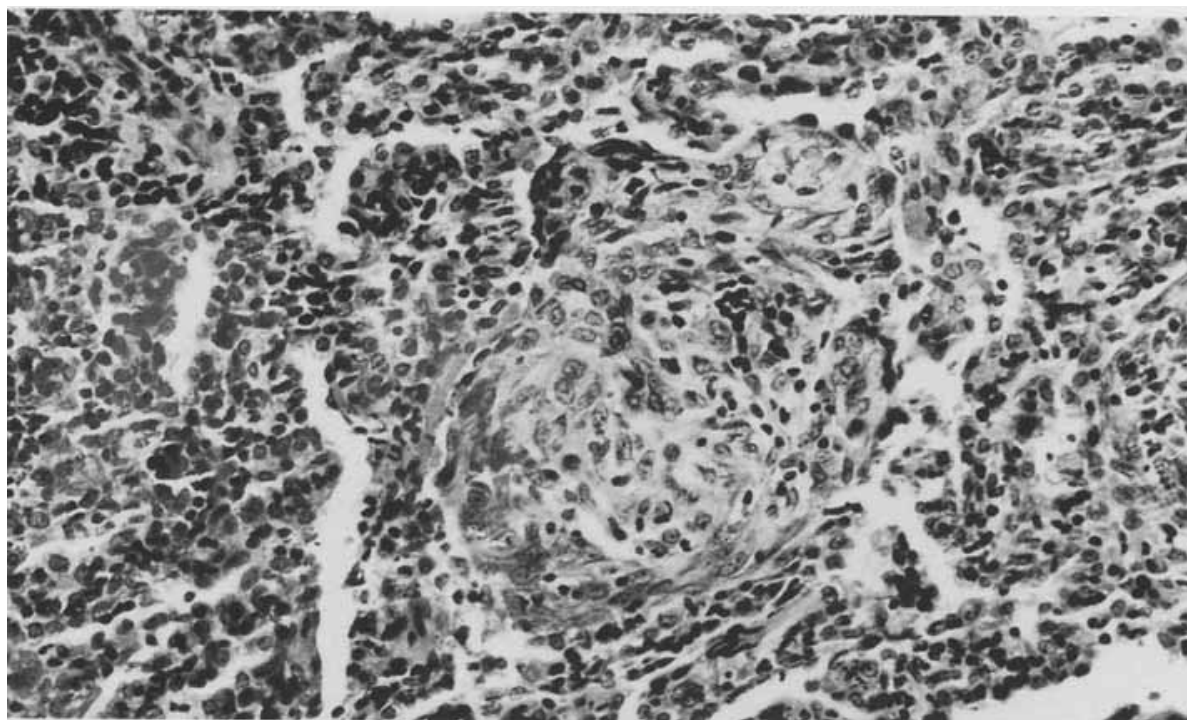

Figure 1.14. Hypersensitivity pneumonia. Mononuclear cells have infiltrated extensively into alveolar walls. In the center is a loosely formed granuloma.

Antibodies with reactivity for the neutrophil granule enzyme, protease 3, give a diffuse cytoplasmic pattern of staining and are relatively characteristic of Wegener's granulomatosis; antibodies reactive against other granule components such as myeloperoxidase tend to stain only the perinuclear cytoplasm and are more common in other types of vasculitis. The possible pathogenetic role of ANCAs in neu- trophil activation is under active investigation [102].

The histologic features of the granulomas of Wegener's granulomatosis are often characteristic $[103,104]$. Necrosis appears to begin with small foci of degenerating neutrophils enclosed by epithelioid histiocytes and giant cells (Figure 1.15). Coalescence of small foci gives rise to large irregular zones of necrosis (geographic necrosis) enclosed by fibrosis

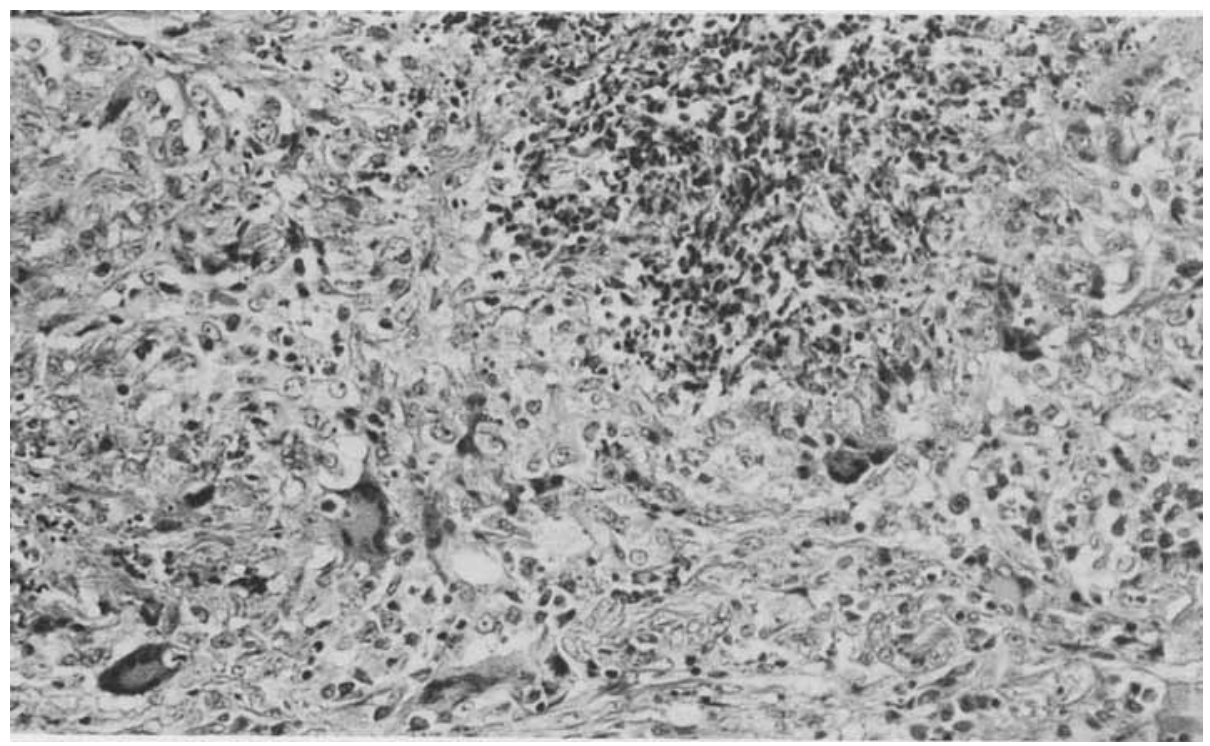

Figure 1.15. Wegener's granulomatosis. A collection of degenerating neutrophils within a zone of granulomatous inflammation with several multinucleated giant cells. 


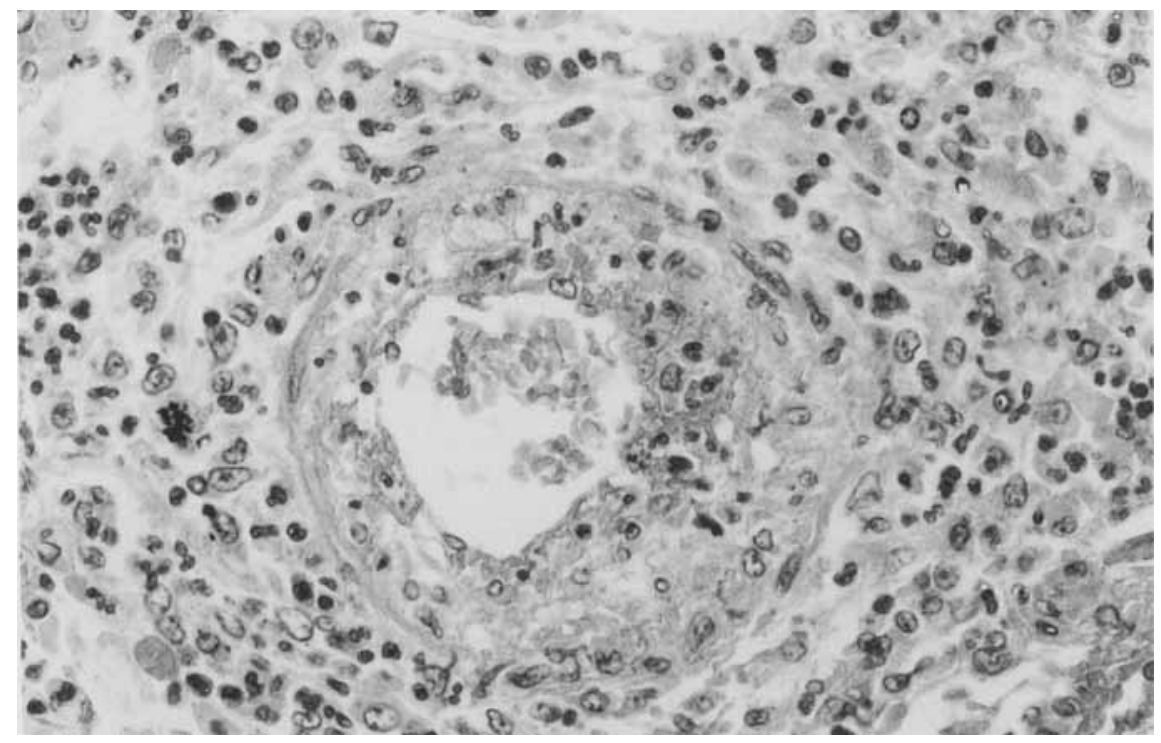

Figure 1.16. Vasculitis in Wegener's granulomatosis.

and granulomatous inflammation (Figure 1.16) Accompanying the inflammatory lesions, the veins and arteries of various sizes are invaded by inflammatory cells. The vascular inflammation may be segmental or concentric, granulomatous, mononuclear or fibrinoid necrosis. Vasculitis of the smallest vessels is termed capillaritis and is associated with pulmonary hemorrhage. The capillaries and venules are infiltrated with neutrophils and often show fibrin deposition in their walls. The neutrophils remain clustered along the alveolar walls, rather than invading the lumen as occurs with pneumonia, and one can readily imagine that the chemotactic stimulus is associated with the septal capillaries rather than being generated in the alveolar space.

A number of histologic variants of pulmonary Wegener's granulomatosis have been recognized in recent years: bronchocentric, eosinophilic, and organizing pneumonia-like which can be misinterpreted by pathologists if they fail to recognize the associated vascular lesions or the presence of a systemic process [105-107].

In the Churg-Strauss syndrome (allergic granulomatosis) the development of a systemic disease follows a prodrome which often begins with nonspecific upper respiratory symptoms and invariably includes asthma, often of several years duration. The systemic disease is characterized by peripheral eosinophilia, vasculitis, and the appearance of extravascular eosinophilic infiltrates and granulomas in several organs including the lung [108].

In addition to the lung, commonly affected organs include the skin, peripheral or central nervous system, gastrointestinal tract, and heart. Pulmonary disease includes both a vasculitis involving small arteries and veins and parenchymal infiltrates which may be patchy and transient, nodular, or diffuse [109]. Biopsy may show an eosinophilic pneumonia with infiltrates of eosinophils, often with the formation of collections of degenerating eosinophils known as eosinophilic abscesses. Macrophages phagocytize the eosinophilic debris giving rise to granulomas often with multinucleated giant cells.

The asthmatic prodrome and peripheral blood eosinophilia usually distinguish Churg-Strauss syndrome from Wegener's granulomatosis. Both diseases may have positive ANCA serology. Churg-Strauss is more likely to have a perinuclear staining pattern and Wegener's a diffuse pattern, but the overlap is sufficient that serology is not a basis for differential diagnosis [102].

Necrotizing granulomas occur in other immunologically mediated diseases. Rheumatoid nodules can appear as single or multiple lesions characterized by palisading histiocytes surrounding necrotic centers. In one pathologic series rheumatoid nodule was the commonest lesion reported on lung biopsy in rheumatoid arthritis, but doubtlessly this reflects need for biopsy of nodules rather than its true incidence [110].

\section{Eosinophilic Lung Diseases}

Eosinophilic lung diseases (pulmonary eosinophilia) are a group of diseases of varied etiology in 
which the lung is infiltrated by large numbers of eosinophils. Peripheral blood eosinophilia is present in some, but not all cases. A contemporary classification of the eosinophilic lung diseases is given in Table 1.1 [111].

The division into these categories is in part clinical. The entities listed for the most part have similar histologic changes which have been described under the term eosinophilic pneumonia [112].

The pathology of eosinophilic pneumonia combines infiltration of the interstitium of the lung with eosinophils, lymphocytes and histiocytes with an intra-alveolar exudate composed mainly of eosinophils and macrophages [112]. The macrophages have round to oval nuclei and do not have the ultrastructural or immunoperoxidase properties of Langerhans' cells indicating that they are ordinary macrophages. Often there are eosinophilic abscesses, intraalveolar foci of degenerating eosinophils surrounded by macrophages which have phagocytosed eosinophil granules and sometimes Charcot-Leyden crystals. Multinucleated histiocytic giant cells may be present. Masson bodies or fibroblastic polyps, often infiltrated with eosinophils, may be present in some respiratory bronchioles and alveolar ducts and rarely are extensive enough to suggest overlap between eosinophilic pneumonia and organizing pneumonia [113]. Some infiltration of blood vessels with eosinophils may be present but true vasculitis is unlikely unless the eosinophilic pneumonia occurs in the context of Churg-Strauss syndrome.

In simple pulmonary eosinophilia (Loeffler's syndrome) peripheral blood eosinophilia accompanies pulmonary alveolar and interstitial infiltrates in the chest roentgenogram. Symptoms are mild or absent and the infiltrates are patchy, peripheral and migratory. Treatment is usually unnecessary as the process resolves spontaneously within a month. Some cases are probably a phase in the life cycle of parasitic infection (via infra).

Acute eosinophilic pneumonia is also of short duration, but is a more fulminant process $[114,115]$.

Table 1.1. Pulmonary eosinophilias

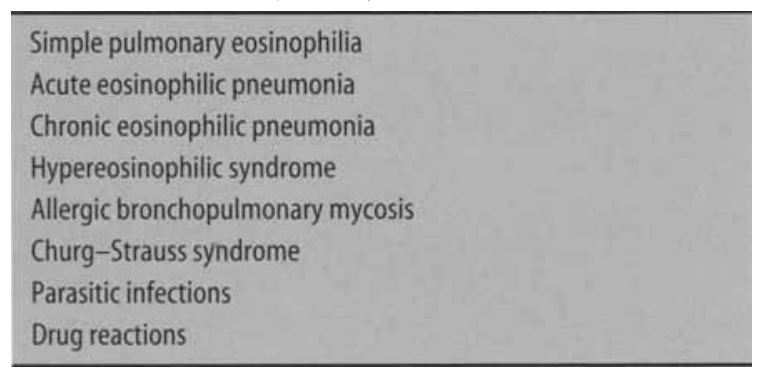

Patients are severely ill with abrupt onset of dyspnea, fever and tachypnea. Chest roentgenogram shows bilateral interstitial infiltrates. Hypoxemia with $\mathrm{PaO}_{2}<60 \mathrm{~mm} \mathrm{Hg}$ or widening of the A-a gradient is present and $50 \%$ of the patients in a recent series required assisted ventilation [115]. In most cases blood eosinophilia is absent and in nearly all cases the presence of lung eosinophilia has been established by bronchoalveolar lavage. The process responds promptly to corticosteroids and does not recur.

Chronic eosinophilic pneumonia is a disease which typically affects middle aged women. The onset of symptoms is gradual. Cough and dyspnea are commonly accompanied by systemic signs such as fever and weight loss. The radiograph classically shows a dense peripheral infiltrate but other patterns can be seen. Blood eosinophilia is present in roughly $50 \%$ of patients. Chronic eosinophilic pneumonia responds well to steroids but relapses are common when steroids are tapered $[116,117]$.

The term hypereosinophilic syndrome describes patients without a known cause of eosinophilia, who have persistent blood eosinophilia greater than 1500 per $\mathrm{mm}^{3}$ lasting 6 months or longer and develop signs of end organ damage. Endomyocardial fibrosis is the most common form of end organ damage but the liver, spleen, kidney, skin and nervous system can be affected. About $40 \%$ of patients have pleural or pulmonary manifestations. Parenchymal disease can be caused by interstitial infiltration of eosinophils with fibrosis or may be caused by pulmonary emboli [111].

Allergic bronchopulmonary aspergillosis and the Churg-Strauss syndrome are discussed elsewhere. Lesions of eosinophilic pneumonia can be seen in either.

Eosinophilic pneumonia with circulating eosinophilia is common in parasitic infections. In the United States Ascaris and Strongyloides are among the most common. The diagnosis may not be made unless the stool is tested weeks after the patient manifests pulmonary disease. The pulmonary infiltrates occur during the phase of larval migration through the lung, but ova do not appear in the stool until worms mature into adults and take up residence in the intestine. Infection with Dirofilaria imitis or Toxocara canis can also cause lung lesions and eosinophilia with negative stools. The dog is the definitive host for both worms and the larvae of neither one can mature in the human. Tropical eosinophilia is a variant of the PIE syndrome caused by immune reactions to filarial worms Wucheria bancrofti and Brugia malayi [118]. The disease is endemic in the Indian subcontinent and southeast Asia, but cases also occur in Central Africa and the 
Philippines. The filaria are transmitted by mosquitoes. The adult worms live in the lymphatics and release microfilaria which cause intense eosinophilic infiltration of the lung. Levels of IgE are elevated and blood eosinophilia $>3000$ per $\mu$ are common. Over the next several months the eosinophils are gradually replaced by macrophages and interstitial fibrosis begins to appear. In cases of several years duration inflammatory cells are few but fibrosis can be severe and even fatal [119].

A large number of drugs can cause eosinophilic pneumonia with or without peripheral blood eosinophilia. One recent review listed more than 40 drugs. Among the commoner are antibiotics, nonsteroidal anti-inflammatory drugs and sulfasalazine. In the eosinophilia-myalgia syndrome, it was a trace contaminant, rather than the dietary supplement $\mathrm{L}$ tryptophan, that caused disease.

\section{Pulmonary Hemorrhage}

Bleeding into the lung has a number of causes including severe hemodynamic stress, pulmonary emboli, diffuse alveolar damage and infectious pneumonia, the latter especially when accompanied by leukopenia and thrombocytopenia. In patients undergoing chemotherapy with autologous bone marrow transplantation, pulmonary hemorrhage is a not uncommon complication with a high mortality $[120,121]$. A group which presents a particular diagnostic challenge is those patients in whom diffuse pulmonary hemorrhage is the result of immunologic or vasculitic injury to alveolar capillaries. The clinical manifestations in the lung and the pulmonary histopathology are rarely distinctive. The specific diagnosis is made after consideration of any systemic manifestations and immunologic findings [122,123].

Clinically, patients with diffuse alveolar hemorrhage usually, but not invariably, experience hemoptysis. Dyspnea, anemia, and a chest radiograph showing alveolar filling are common. The presence of hemorrhage can be inferred from a supranormal carbon monoxide uptake or directly demonstrated by bronchoalveolar lavage or biopsy. In acute pulmonary hemorrhage, the alveoli contain fresh blood and fibrin. After a few days hemosiderin appears in macrophages and there may be focal evidence of intralveolar organization. Alveolar septa may be thickened by edema and the type II alveolar cells are hyperplastic. Neutrophils or mononuclear cells are often present in alveolar walls. Capillaritis, fibrin deposition or necrosis of alveolar capillaries with neutrophils clustered within or along the affected septa, is typical of vasculitis [124], but can be seen in diffuse alveolar hemorrhage of varied immunologic mechanisms [122]. With chronic or repeated hemorrhage, siderophages become numerous. The alveolar septa become fibrotic. Hemosiderin and calcium can encrust perivascular elastic fibers and elicit foreign body giant cells.

The immunologic findings in various diseases associated with diffuse pulmonary hemorrhage are summarized in Table 1.2. Although capillaritis occurs in a minority of all patients with Wegener's granulomatosis, it is virtually always present in those with diffuse pulmonary hemorrhage [125]. ANCA are present in more than $90 \%$ of those with active disease but may be negative during remission. Classically immunofluorescence on lung or kidney is negative, but a few cases have evidence of granular staining for immunoglobulin and complement. Microscopical polyarteritis nodosa (hypersensitivity angiitis) is a systemic vasculitis involving small arteries, arterioles, and capillaries. ANCA is usually positive, and immunofluorescence negative. Commonly involved tissues include skin, kidney, lung and spleen. Certain rare forms of vasculitis, including Behçet's syndrome and Henoch-Schönlein purpura usually have evidence of immune complex deposition.

The combination of rapidly progressive glomerulonephritis (RPGN) and pulmonary hemorrhage has several causes. Currently, the eponym Goodpasture's disease is restricted to those cases with antiglomerular basement membrane (GBM) antibodies $[126,127]$. These antibodies are mainly directed to the non-collagenous carboxy terminal domain of the alpha 3(IV) chain of basement membrane (type IV) collagen $[127,128]$. Antibodies to other alpha chains of type IV collagen occur, but evidence from animal experiments suggests that antibodies to the alpha 3 (IV) chain are more pathogenic. Anti GBM

Table 1.2. Capillaritis and immunologic features of diffuse pulmonary hemorrhage

\begin{tabular}{lcccc}
\hline Disease & Capillaritis & ANCA & AGBM & IC \\
\hline WG & + & + & - & \\
Rarely & & & & - \\
MPAN & + & + & - & + \\
SLE & \pm & - & - & + \\
Cryoglobulinemia & $?$ & - & - & + \\
Goodpasture & \pm & - & + & + \\
RPGN + DPH & \pm & - & - & \pm \\
Isolated DPH & \pm & \pm & \pm & \pm \\
\hline Abbreviations: WG, Wegener's granulomatosis; MPAN, Microscopic \\
polyarteritis nodosa; SLE, Systemic lupus erythematosus; RPGN, Rapidly \\
progressive glomerulonephritis; DPH, Diffuse pulmonary hemorrhage; \\
ANCA, Antineutrophil cytoplasmic antibody; AGBM, Antiglomerular \\
basement membrane antibody; IG, Immune complexes. \\
Symbols: + present,-absent, \pm present in some cases but absent in others.
\end{tabular}


antibodies can also cause either RPGN or pulmonary hemorrhage without the other. RPGN with pulmonary hemorrhage can also occur with immunofluorescent granular staining indicative of immune complex deposition or with negative immunofluorescence.

As noted above, isolated pulmonary hemorrhage occurs infrequently as a manifestation of disease associated with anti GBM antibodies. Most cases of isolated pulmonary hemorrhage, however, have negative immunofluorescence and to these the term idiopathic pulmonary hemorrhage (or hemosiderosis) is applied. Although negative immunofluorescence is the usual result, in one recent series $2 / 4$ cases had immunofluorescent results compatible with immune complex deposition. In another small series $3 / 4$ patients had a positive ANCA test [129]. These results suggest that some cases of idiopathic pulmonary hemorrhage have immunologic mechanisms similar to pulmonary hemorrhage associated with extrapulmonary disease.

\section{Miscellaneous Conditions}

\section{Alveolar Proteinosis}

Alveolar proteinosis is a disease characterized by the accumulation within air spaces of granular eosinophilic material rich in pulmonary surfactant. In microscopic sections this material can be distin- guished from edema fluid by its granular texture and its content of cholesterol clefts and homogeneous eosinophilic blobs 5-20 microns in diameter which have been shown by electron microscopy to be anucleated remnants of cells $[130,131]$ (Figure 1.17).

Patients with alveolar proteinosis gradually develop dyspnea and non-productive cough. Characteristically, the chest roentgenogram shows a severe alveolar filling process that is out of proportion to the relatively mild symptoms. By computed tomography, the distribution of lesions within lung lobules is highly variable [132]. The natural history of the disease varies: some patients improve spontaneously, others progress and require therapeutic bronchoalveolar lavage.

The cause of most cases of alveolar proteinosis is unknown. Workers exposed to especially high concentrations of silica of small particle size can develop a form of proteinosis called acute silicoproteinosis in which air spaces are filled with a typical proteinosis-type exudate usually accompanied by interstitial foci containing duct-laden macrophages [133]. In so-called secondary alveolar proteinosis, a proteinosis-like exudate is seen in air spaces of subjects who are immunosuppressed or have hematologic malignancy $[134,135]$. The exudate stains less intensely for surfactant apoprotein $A$ than does the exudate in idiopathic alveolar proteinosis, suggesting that in the secondary form the exudate contains other sources of protein such as fibrin or cell debris [136].

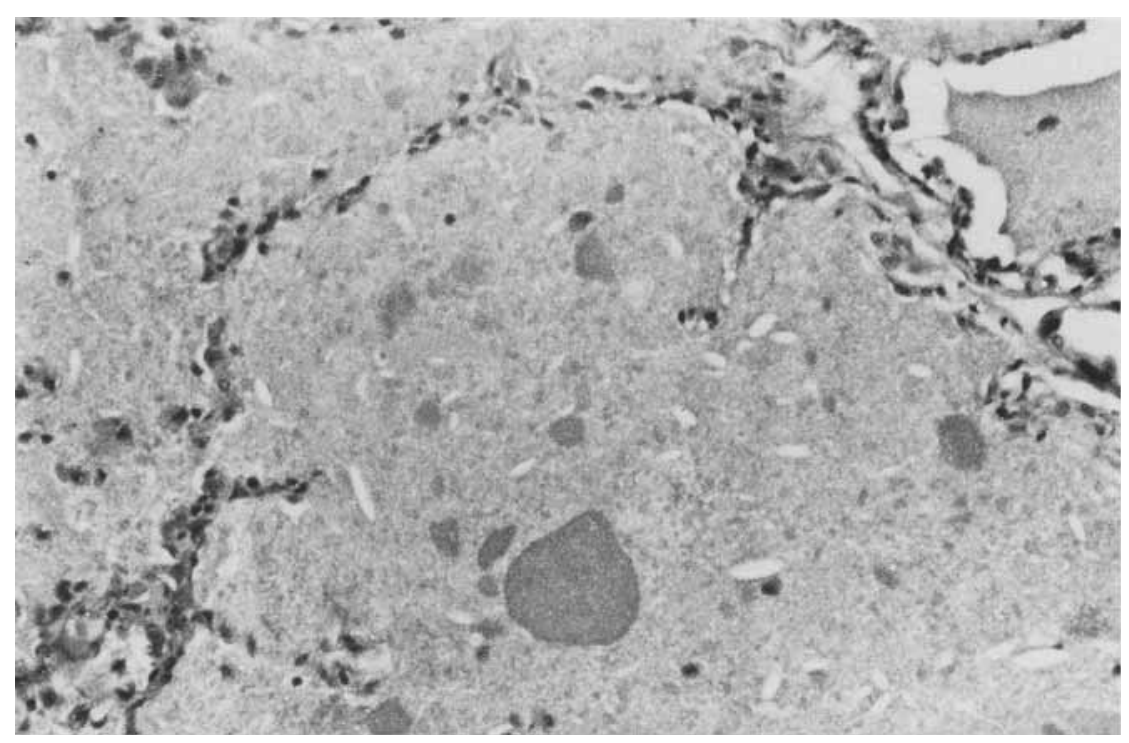

Figure 1.17. Alveolar proteinosis. The air spaces are filled with granular material within which are cholesterol clefts and 'blobs' of eosinophilic material similar in size to cells. The alveolar septa are thin with minimal inflammation. 
Congenital alveolar proteinosis is a familial form of proteinosis that presents in the newborn period. Most cases are caused by mutations in the gene encoding the surfactant protein B leading to an absence of this protein. Secondary changes include excessive accumulation of surfactant proteins $A$ and $\mathrm{C}$ as well as evidence of cell injury $[137,138]$.

In two animal models of alveolar proteinosis, the abnormal accumulation of surfactant in the air spaces is the consequence of impaired catabolism, and indirect evidence indicates a similar pathogenesis in man $[139,140]$.

Alveolar proteinosis is sometimes complicated by infections, most often by Nocardia or Mycobacteria [141]. The alveolar macrophages which are filled with lipid droplets and proteinaceous material may become ineffective in phagocytosis or microbial killing [142].

\section{Pulmonary Calcifications and Ossification}

Calcium deposition can be either dystrophic or metastatic. In dystrophic calcification the calcium is deposited in abnormal, often necrotic tissue and plasma concentrations of calcium and phosphorus are normal. In metastatic calcification the calcium is deposited in normal tissue as a consequence of hypercalcemia or hyperphosphatemia. Dystrophic calcification is usually focal but extensive calcification can sometimes be seen radiographically after the healing of chicken pox pneumonia, histoplasmosis or in silicosis. Diffuse metastatic calcification is seen in some patients with hypercalcemia of any cause or in renal failure. The calcium deposition occurs in the basement membranes and elastic fibers of the alveolar ducts, alveolar walls, and small blood vessels. Often the calcification is accompanied by fibrosis, which is thought to be a reaction to the calcifications. The calcification is rarely sufficiently extensive to be detectable in the plain chest radiograph but can restrict ventilatory function [143]. The diagnosis can conveniently be made by scintigraphy using bone-seeking radionuclides [144].

Ossification in the lung also is of two types, nodular and racemose [145]. Nodular ossification occurs as intra-alveolar spicules of bone without marrow in patients with severe pulmonary congestion, especially with mitral stenosis. The mechanism is unknown. Racemose ossification usually forms in the interstitium in cases of chronic pulmonary fibrosis. The bone takes the form of branching twiglike trabeculae which sometimes contain marrow. Occasional trabeculae form within air spaces as well. Both nodular and racemose ossification can be visible radiographically.
Alveolar microlithiasis is a rare and poorly understood cause of pulmonary calcifications. Approximately $50 \%$ of cases are familial, most appearing in siblings. Most patients are adults at the time of diagnosis although onset can be at any age.

Pathologically, the disease is characterized by the formation within alveolar spaces of concentrically laminated, calcium phosphate-containing calcispherites up to several hundred microns in diameter. Rarely spherites can form within fibrotic interstitium and in the walls of airways. The calcispherites often impart characteristic sand-like densities to the chest roentgenogram. The diagnosis has been confirmed by demonstrating the uptake of bone-seeking radionuclides and by retrieving the calcispherites by bronchoalveolar lavage. The natural history varies. Some patients are asymptomatic and progress slowly if at all, but others have progressive restrictive lung disease $[146,147]$.

\section{Amyloidosis}

Amyloidosis affects the lung alone or as part of systemic amyloidosis [148]. Bronchial involvement by amyloidosis can produce single or multiple submucosal deposits which can be plaque-like, polypoid, or concentric, but generally produce clinical signs as a result of bronchial obstruction. Parenchymal nodules can be single or multiple. When single they are usually asymptomatic and are discovered as incidental radiographic abnormalities. Multiple nodules are symptomatic in approximately half of those affected. Nodules, single or multiple, are circumscribed collections of eosinophilic amorphous material embedded in a scanty fibrous stroma containing abundant plasma cells. Multinucleated giant cells are applied to the surface of the amyloid deposits. Bone and cartilage metaplasia are common within the amyloid. Diffuse septal amyloidosis is usually a manifestation of systemic primary amyloidosis or amyloidosis associated with multiple myeloma, but cases limited to the lung do occur. The amyloid is deposited within the alveolar septa and blood vessels, generally preserving the lung architecture, but eventually obliterating capillaries (Figure 1.18). Clinical manifestations often are overshadowed by cardiac involvement, but respiratory insufficiency can also occur [149].

Both the nodular and diffuse septal amyloidosis usually contain immunoglobulin light chain fragments, have a fibrillar ultrastructure, and give the classical staining reactions including birefringence after Congo red staining. A few cases of L-chain deposition disease have been described which have all the typical features of amyloid by hematoxylineosin stains but failed to give the classical staining 


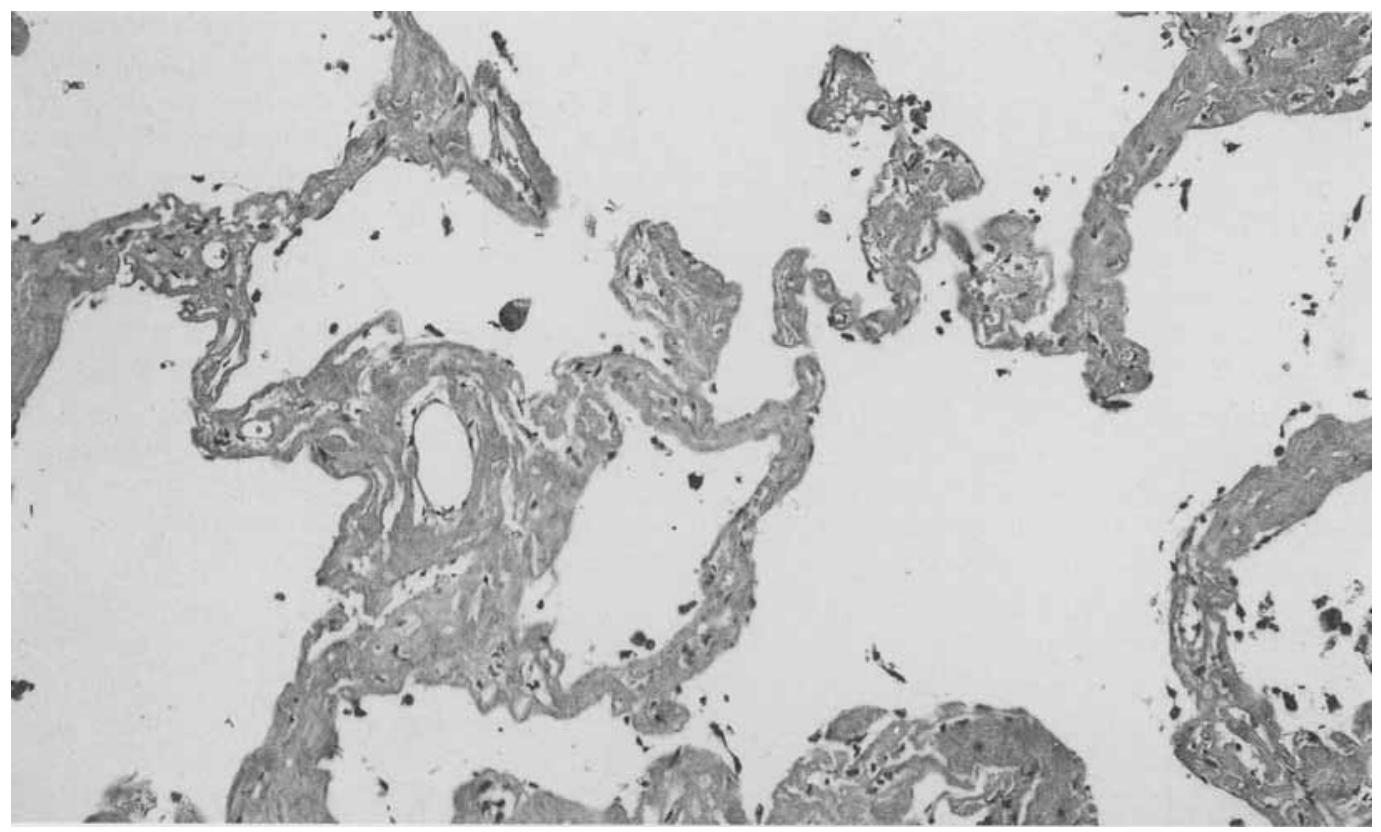

Figure 1.18. Diffuse septal amyloidosis. The interstitium is filled with homogeneous eosinophilic material which has obliterated many of the septal capillaries.

reactions for amyloid or to show fibrils by electron microscopy. Most have had Kappa light chains [150].

\section{Pulmonary Involvement in Collagen-Vascular Disease}

The lung can be involved in virtually all of the socalled collagen-vascular diseases $[151,152]$. A few localized manifestations such as rheumatoid nodules and some examples of rheumatoid pleurisy have relatively specific histologic features [153]. Diffuse lung disease in the collagen vascular diseases is extraordinarily varied in its manifestations but the histological features are non-specific. The assumption that the lung disease is a manifestation of the underlying collagen-vascular disease is based on clinical experience and in some instances immunological mechanisms.

\section{Rheumatoid Arthritis}

Pulmonary disease in rheumatoid arthritis (RA) illustrates the range of lesions that can be seen (Table 1.3) [154]. Bronchiectasis is a commoner in rheumatoid arthritis than would be expected, whether as a complication of infection or a manifestation of the primary disease [155]. Pure obliterative bronchiolitis (with airflow obstruction and without
Table 1.3. Diffuse pulmonary lesions associated with rheumatoid arthritis

\begin{tabular}{l}
\hline Bronchiectasis \\
Bronchiolitis obliterans \\
Bronchocentric granulomatosis \\
Lymphoid hyperplasia \\
Diffuse alveolar damage \\
Organizing pneumonia \\
Usual interstitial pneumonia \\
Desquamative interstitial pneumonia \\
Non-specific interstitial pneumonia \\
Microgranulomas \\
Pulmonary vasculitis \\
\hline
\end{tabular}

acinar disease) is a recognized association with RA. It has been attributed by some to penicillamine, but not all patients have been treated with penicillamine, suggesting that it is a manifestation of the primary disease [156]. The full range of fibrosing and interstitial pneumonia patterns can be seen in biopsies from patients with RA and diffuse infiltrates on their chest roentgenograms. The histologic patterns are predictive of outcome. Just as with patients with idiopathic interstitial lung disease, patients with organizing pneumonia or DIP patterns tend to respond favorably to therapy while those with UIP follow a progressive and generally fatal course $[110,157]$. 


\section{Systemic Lupus Erythematosus}

Diffuse lung involvement in lupus erythematosus includes three forms of infiltrative lung disease, pulmonary hemorrhage, acute lupus pneumonitis and chronic interstitial fibrosis [158]. Diffuse pulmonary hemorrhage, as already discussed is usually a form of immune complex-mediated capillary injury although rare cases without immune complexes have been reported. Typical cases with immune complex deposition show dense deposits in the subendothelial space by electron microscopy and granular staining for IgG and complement deposition by immunoflourescence $[159,160]$. The alveolar septa may show little change by light microscopy, or may show mild thickening by edema, neutrophil infiltration and epithelial regeneration. Acute lupus pneumonitis pathologically resembles diffuse alveolar damage from other causes [161]. DNA-anti DNA immune complexes have been identified by immunohistochemistry and elution [162]. Chronic fibrosis is the least common type of involvement, and patients often have scleroderma-like features.

Pulmonary hypertension also occurs in systemic lupus erythematosus. It may result from vasculitis or show plexiform lesions like those of primary pulmonary hypertension [163].

\section{Progressive Systemic Sclerosis (PSS)}

The skin, kidney, and gastrointestinal tract are involved more frequently than the lung in progressive systemic sclerosis (PSS), but pulmonary disease is the leading cause of death. The two main forms of pulmonary disease are pulmonary fibrosis and pulmonary vascular disease [164]. Pulmonary fibrosis has clinical and morphologic characteristics of UIP and a relatively indolent course [165]. Pulmonary vascular lesions can occur with or without diffuse fibrosis, but are especially common in the CREST variant of PSS [166]. In the active stages the pulmonary arteries show a characteristic marked myxoid intimal thickening with concentric proliferation of smooth muscle cells which progresses to intimal fibrosis. In mild cases, vascular disease without fibrosis can cause an isolated reduction in diffusing capacity. With more severe vascular disease pulmonary hypertension develops [167].

\section{Polymyositis and Dermatomyositis}

Respiratory symptoms in dermatomyositis and polymyositis can result from muscle weakness, aspiration or from infiltrative lung disease. Three main morphologic patterns of infiltrative lung disease are diffuse alveolar damage, organizing pneumonia and usual interstitial pneumonia.

Cases with diffuse alveolar damage follow a course of rapid deterioration with a high mortality, those with organizing pneumonia often stabilize or clear on therapy and those with UIP follow a course of gradual deterioration [168].

\section{Sjögren's Syndrome}

In Sjögren's syndrome the same lymphocytic infiltration that affects salivary and lacrimal glands can destroy bronchial mucus glands causing a dessication of airway secretions and bronchial infection [169]. Small airways dysfunction can be detected in many patients with Sjögren's syndrome and some have severe cellular bronchiolitis. Three to four percent of patients have a non-specific pattern of interstitial pneumonia [170]. Lymphoproliferative lesions can take either a diffuse form (lymphoid interstitial pneumonia) or multifocal discrete nodules of hyperplastic lymphoid tissue composed of germinal centers in a polyclonal lymphoplasmacytic background (pseudolymphoma). Malignant lymphomas occur in the lung as in other tissues in Sjögren's syndrome, and most are high grade B-cell lymphomas $[171,172]$.

\section{Drug-induced Diffuse Lung Disease}

The list of drugs implicated as causes of diffuse lung disease is long and a number of comprehensive reviews are available $[173,174]$. Some drug effects are not detectable morphologically such as respiratory depression or bronchospasm. The morphologic effects of most others are non-specific. Consequently, the attribution of a pulmonary lesion to drugs is a matter of exclusion and precedent. Withdrawal of the drug often leads to reversal of the pulmonary lesion but exceptions occur. Some diseases progress after the drug is stopped and the onset of the pulmonary disease after completion of drug therapy has been reported for some classes of drugs.

Two broad classes of drug-effects are toxic and idiosyncratic. Toxic effects are generally doserelated and predictable, whereas idiosyncratic reactions occur in only a small fraction of subjects taking a drug at a given dose and often represent hypersensitivity reactions. Synergism between drugs or between radiation and drugs further complicates dose-response relationships.

Table 1.4 lists different histopathologic types of drug reactions and selected examples of each. 
Table 1.4. Examples of pulmonary reactions to drugs

\begin{tabular}{|c|c|}
\hline Tissue reaction & Drugs \\
\hline Edema & $\begin{array}{l}\text { Ethchlorvynol, haloperidol, } \\
\text { propanol, salcylates }\end{array}$ \\
\hline Diffuse alveolar damage & $\begin{array}{l}\text { Alkylating agents, bleomycin, gold } \\
\text { salts, Methotrexate, hexamethonium }\end{array}$ \\
\hline Organizing pneumonia & $\begin{array}{l}\text { Alkylating agents, amiodarone, } \\
\text { bleomycin, gold salts, methotrexate, } \\
\text { sulfasalazine }\end{array}$ \\
\hline $\begin{array}{l}\text { Chronic interstitial pneumonia } \\
\text { (UIP, DIP) }\end{array}$ & $\begin{array}{l}\text { Alkylating agents, amiodarone, } \\
\text { bleomycin, methotrexate, } \\
\text { nitrofurantoin, sulfasalazine }\end{array}$ \\
\hline Eosinophilic pneumonia & $\begin{array}{l}\text { Bleomycin, nitrofurantoin, } \\
\text { minocycline, sulfasalazine }\end{array}$ \\
\hline $\begin{array}{l}\text { Hypersensitivity pneumonia } \\
\text { (granulomatous) }\end{array}$ & Methotrexate, minocycline \\
\hline Phospholipidosis & Amiodarone, chlorphentermine \\
\hline $\begin{array}{l}\text { Pulmonary hypertension } \\
\text { with Plexiform arteriopathy }\end{array}$ & $\begin{array}{l}\text { Aminorex, fenfluramine, } \\
\text { dexfenfluramine }\end{array}$ \\
\hline $\begin{array}{l}\text { Constrictive bronchiolitis } \\
\text { obliterans }\end{array}$ & Penicillamine, gold salts \\
\hline
\end{tabular}

Noteworthy is that the same drug can produce several types of tissue response and produce both toxic effects and hypersensitivity reactions.

Alkylating agents used in cancer chemotherapy are a major cause of pulmonary toxicity. The first member of this class to be recognized as a cause of toxic lung disease was busulfan [175], but others produce similar lesions. The pathologic changes usually correspond to an organizing diffuse alveolar damage. Epithelial atypia are a well documented effect of busulfan, but bizarre regenerating epithelium is common in diffuse alveolar damage of any cause and consequently atypia is not useful for pathologic differential diagnosis. Synergism between radiation and alkylating agents in producing lung toxicity is believed to occur. Delayed onset of lung disease was reported as long as 17 years after therapy with BCNU [176].

Bleomycin pulmonary toxicity is usually doserelated appearing once a cumulative dose of $400 \mathrm{mg}$ has been exceeded. The pathology usually is an organizing diffuse alveolar damage which is readily reproduced in animals. Occasional patients develop lung disease after only a few doses or have eosinophilic lung disease suggesting hypersensitivity.

Methotrexate-induced lung disease can appear during low dose therapy. It often takes the form of a diffuse infiltrate of mononuclear cells with poorly formed granulomas resembling hypersensitivity pneumonia. Evidence of lymphocytosis in bronchoalveolar lavage fluid and sensitization of blood lymphocytes also suggest hypersensitivity [177].

Amiodarone is a useful antiarrythmic drug which causes an accumulation of phospholipid inclusions in many cell types including alveolar macrophages (Figure 1.19). This is probably the result of direct inhibition of phospholipase A by the drug and is not of itself a sign of toxicity. It is a mark of exposure to the drug, but only when accompanied by radiographic, physiologic or pathologic evidence of fibrosis should a diagnosis of amiodarone pulmonary toxicity be made [178].

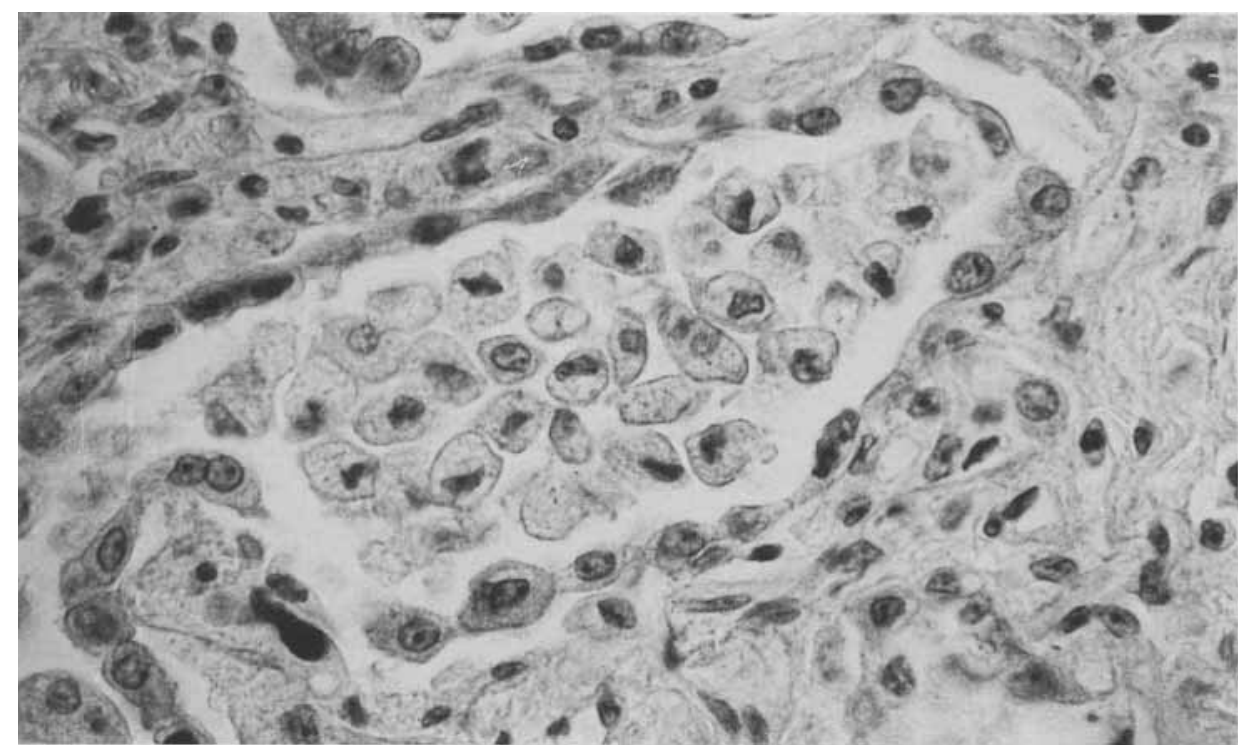

Figure 1.19. Amiodarone-induced pulmonary fibrosis. The cytoplasm of the alveolar macrophages has a finely vacuolated appearance owing to the presence of phospholipid inclusions. 


\section{Radiation}

The effect of radiation on the lung depends on the total dose of radiation, the degree of fractionation and the volume of lung irradiated [179]. A dose of $30 \mathrm{~Gy}$ to the whole lung is fatal, yet therapeutic doses higher than this are commonly received by small volumes of lung during therapy for localized lesions. Under such circumstances radiation damage is limited to the irradiated tissue volume, and radiographic changes are common, occurring in nearly $50 \%$ of patients. Symptomatic radiation pneumonitis occurs in only $5 \%-10 \%$. Radiation pneumonitis has its onset 1-3 months after completion of therapy. Its clinical manifestations are nonspecific and severity is related, among several factors, to the volume of tissue treated. Pathologic changes are those of diffuse alveolar damage within the affected tissue volume $[180,181]$. With or without treatment the pneumonitis may subside or may organize and ultimately culminate in radiation fibrosis. Radiation fibrosis again is limited to the irradiated tissue volume which shows dense fibrosis. In mature radiation fibrosis, i.e., past $1-2$ years, the morphology is distinctive in that there are few inflammatory cells and no fibroblast foci, i.e., signs of continuing fibroblastic activation. The interstitium is greatly thickened by poorly cellular fibrillar collagen and the fibroblasts present are often small but multinucleated reflecting damage to the mitotic apparatus. Airways and especially vessels also show fibrosis $[180,181]$.

For many years it has been known that rarely individuals irradiated in one lung develop bilateral pneumonitis. Recently, the occurrence of roentgenographic pulmonary infiltrates was observed which began in local sites of radiation injury but subsequently recurred in other parts of the lung $[182,183]$. The histology was that of organizing pneumonia. The mechanism for the occurrence of radiation-associated injury outside the radiation ports is unclear. However, radiation to one lung causes a bilateral lymphocytosis in bronchoalveolar lavage in most patients suggesting the remainder of the lung may be primed for a hypersensitivity reaction $[184,185]$.

\section{Pneumoconiosis}

The response of the lung to the inhalation of mineral dust varies according to the composition of the dust, dose, particle size and the immunological state of the host. The pathology of a limited selection of the pneumoconiosis follows. For a compre- hensive review the reader can consult specialty textbooks $[186,187]$.

\section{Coal-worker's Pneumoconiosis (CWP)}

The fundamental lesion of simple coal-worker's pneumoconiosis (CWP) is the accumulation of duct laden macrophages in the walls of the respiratory bronchioles and the adventitia of their accompanying arteries. This stimulates a variable amount of fibrosis. By convention, pathologists distinguish macules which are visible but not palpable from nodules which have sufficient collagen to be palpable [188]. These lesions are intimately associated with dilation of the respiratory bronchioles to produce a form of centriacinar emphysema known as focal dust emphysema. As a rule focal dust emphysema is mild unless the worker is also a smoker. Studies have shown that the dust and collagen content of the lesions correlate significantly with radiographic category.

Lesions greater than $1 \mathrm{~cm}$ in diameter are designated complicated pneumoconiosis or progressive massive fibrosis (PMF). Some evidently arise by conglomeration of individual nodules. Others appear to be a single large lesion. In most cases the lesions of progressive massive fibrosis are bilateral and involve the upper lobes. They are heavily pigmented and rubbery. Cavities may form either by ischemic degeneration or infection. The pathogenesis of progressive massive fibrosis is unclear. Lungs with a high dust content and background of nodules are more prone to PMF [189]. A role for silica has been discussed but PMF can develop in those such as carbon electrode workers with no silica exposure. Tuberculosis evidently can trigger PMF but is currently implicated in only a small minority of cases.

Rheumatoid pneumoconiosis is a hybrid lesion seen in miners who coincidentally have rheumatoid arthritis. The lesions are rounded, upper lobe densities $0.5-2 \mathrm{~cm}$ in size and are usually multiple. Like conventional rheumatoid nodules, they have a central necrotic core surrounded by palisading histiocytes but the latter are laden with dust. Concentric layers of dust may be present within the necrosis as well. Rarely, cases have been reported in miners who had positive serologic tests for rheumatoid factor, but no overt arthritis.

Other lesions seen in coal workers include diffuse interstitial fibrosis and typical silicotic-hyaline nodules. The latter are commoner in certain specialities such as roof bolters who are required to drill into solid rock and in locomotive operators who use sand on the rails to increase traction. 


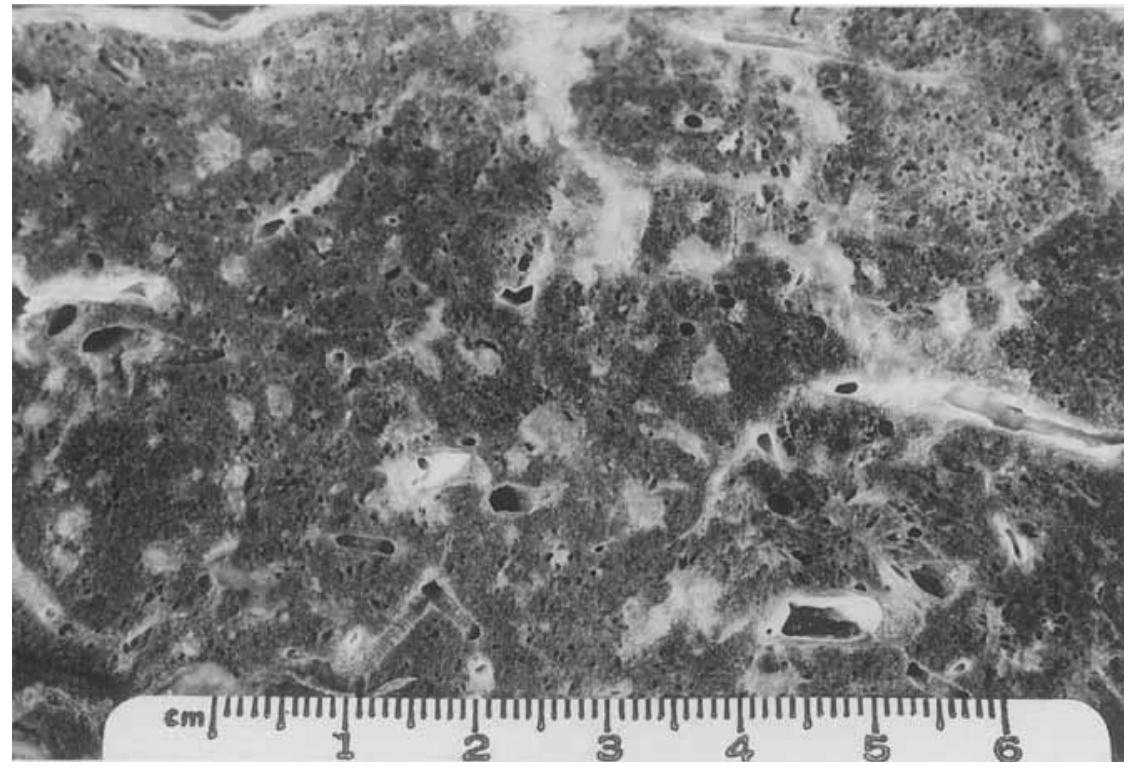

Figure 1.20. Gross appearance of silicotic nodules.

\section{Silicosis}

Acute silicosis is a rare disease seen in those with massive exposure [133]. The onset and clinical disease is a few months to a few years after the start of exposure. It resembles alveolar proteinosis pathologically. In contrast, more typical silicosis is seen in those with exposure for several decades. The characteristic lesion of chronic silicosis is the hyaline nodule [190] (Figure 1.20). These lesions are one to several millimeters in diameter, composed of a central fibrous core of concentrically arranged collagen fibers. The core is poorly cellular but macrophages laden with dust encircle the core, accompanied by fibroblasts and some lymphocytes. Calcium may be deposited in the cores of some of the hyaline nodules. Chronic silicosis has a notable upper lobe predominance and hilar lymph adenopathy caused by the presence of fibrosis and hyaline nodules in the nodes [190].

Radiographically, silicosis is characterized by fine nodularity with an upper lobe predominance. The involved lymph nodes may show a characteristic peripheral ('egg shell') calcification.

Complicated silicosis is defined by the presence of lesions exceeding $1 \mathrm{~cm}$ in diameter. These lesions usually arise via conglomeration of hyaline nodules. They predominate in the upper lobes and may cavitate as a result of either ischemia or infection (Figure 1.21).

Simple silicosis is usually asymptomatic. Some patients have evidence of airflow obstruction, but this can be explained by associated emphysema which is related in part to smoking but can be detected by computed tomography in some nonsmokers with simple silicosis [191]. Complicated pneumoconiosis is often associated with dyspnea. It can progress without continued exposure and in some patients culminates in respiratory failure.

Silicosis predisposes to mycobacterial infection by both $M$. tuberculosis and atypical Mycobacteria. In countries where tuberculosis is common, mycobacterial infection is a significant risk factor for PMF [192].

So-called mixed dust pneumoconiosis results from exposure to silica in combination with other less fibrogenic dusts such as carbon or iron. The mixture modifies the pathologic response so that the nodules are stellate rather than round. The collagen is deposited in interlacing linear bands, and the dust is distributed uniformly throughout the lesion rather than being concentrated in a ring at the periphery of the lesion as is the case in typical silicosis. Typical hyaline nodules and stellate mixed dust lesions can sometimes be found in the same lung. The clinical features of patients with mixed dust exposure are similar to those of silicosis of similar categories.

\section{Asbestosis}

The association of asbestos with pleural effusions, plaques, rounded atelectasis and mesotheliomas are well established [193,194]. The forms of diffuse 


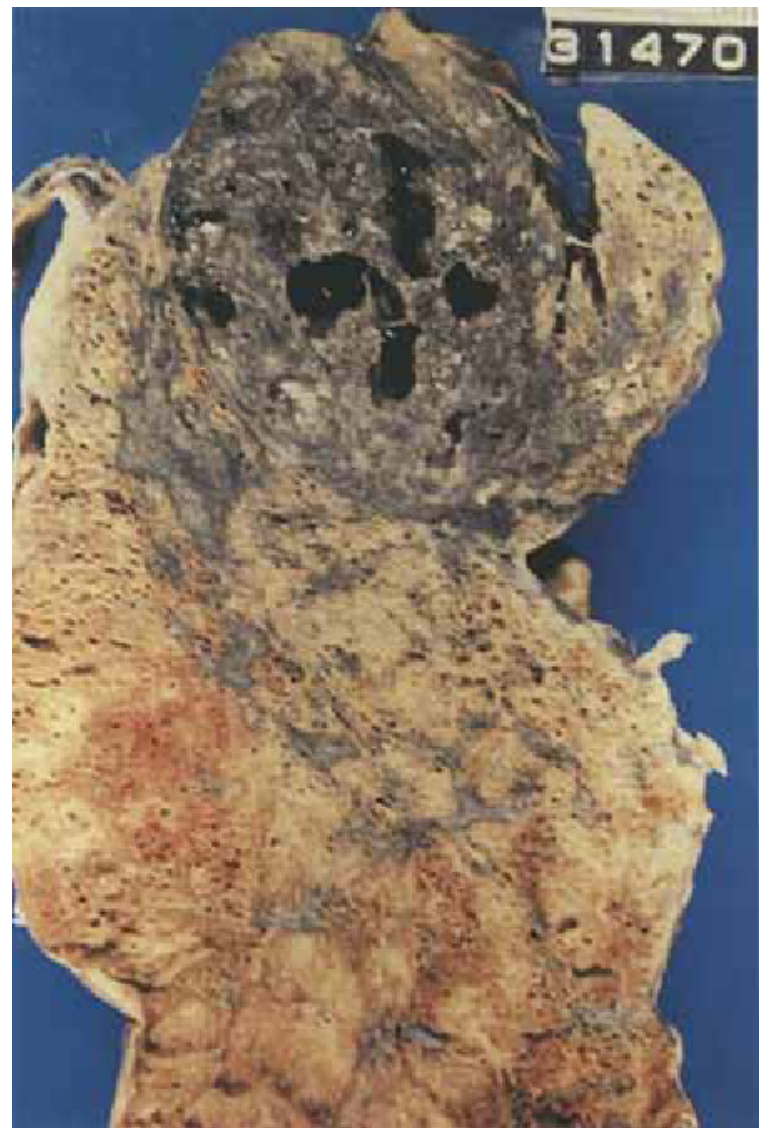

Figure 1.21. Progressive massive fibrosis with silicotuberculosis. The large black mass is cavitating. The small yellow foci within it are tuberculous lesions.

parenchymal disease caused by asbestos are asbestosinduced small airways disease and asbestosis.

Mineral dust small airways disease is a reaction common to a number of dusts including silicates, silica and iron and but tends to be more severe with asbestos [195,196]. It is characterized by fibrosis, most severe in the walls of respiratory bronchioles but often extending into proximal alveolar ducts and into membranous bronchioles. It is qualitatively similar to tobacco smoke-induced small airways disease, but usually more severe and widespread. When associated with asbestos exposure asbestos bodies are often, but not invariably, detected by histology [196]. The fibrosis in asbestos-induced small airways disease can distort the airways and therefore is likely to cause airflow obstruction, but this has not been proven. It is controversial whether asbestos-induced small airways disease is an early stage of abestosis.

Asbestosis is a term reserved for diffuse pulmonary fibrosis caused by inhalation of asbestos
[193]. In routine pathologic practice, this means pulmonary fibrosis accompanied by the presence of asbestos bodies. Asbestos bodies form on a small fraction of all the asbestos fibers in the lung by the deposition of hemosiderin by macrophages on the surface of the fiber. This results in golden brown, often beaded or drum-stick shaped, structures tens of microns in length with the original fiber as a transparent core. Because of asbestos in the environment, literally all adult lungs contain some asbestos bodies if digestion of a tissue sample is carried out, but the ordinary 5 micron histologic section is an inefficient technique for detecting asbestos bodies, so that a single asbestos body per section can be taken as a significant tissue burden.

The tissue response to asbestos generally corresponds to usual interstitial pneumonia, much less commonly to desquamative interstitial pneumonia. Like usual interstitial pneumonia from other causes it results in honeycomb changes visible macroscopically and radiographically, usually with a lower zone predominance. Progression of disease after cessation of exposure is well documented.

There is a well documented increased risk of bronchogenic carcinoma in patients with asbestosis and indeed bronchogenic carcinoma may be the commonest cause of death in patients with asbestosis. Whether the risk is also increased in asbestos workers without asbestosis is controversial [197-200].

\section{Berylliosis}

Berylliosis can cause two syndromes in the lung. Very high doses of beryllium can cause a diffuse chemical pneumonia with the histologic features of diffuse alveolar damage. Once it was recognized, improved industrial hygiene virtually eliminated this form of beryllium disease. Chronic beryllium disease develops months to years after the beginning of exposure. It closely resembles chronic hypersensitivity pneumonia immunologically and histologically. A review of cases in the beryllium case registry showed three patterns of histology: (1) a diffuse mononuclear cell infiltration of the interstitium, (2) a mixture of diffuse mononuclear infiltration with poorly formed non-caseating granulomas resembling those of hypersensitivity pneumonia, (3) well formed epithelioid granulomas with a relatively sparse inflammatory background indistinguishable from sarcoidosis [201]. Giant cells are common in granulomas and frequently contain concentric laminated calcific inclusions called Schaumann or conchoid bodies. Larger hyalinized nodules surrounded by a fibrous capsule are present in $40 \%$ of cases. 
Prognosis correlates with histology. The patients in the registry who had a diffuse mononuclear histology had a $75 \%$ mortality with an average survival of 8 years, whereas the patients with the sarcoid-like reaction had a negligible mortality [201].

Much evidence supports a T-cell mediated mechanism for berylliosis. T-cells in the blood and bronchoalveolar lavage fluid of patients with chronic berylliosis proliferate in response to beryllium salts. Experimental sensitivity to beryllium in the guinea pig is transferred with lymphocytes and not serum. The mechanism of sensitization of lymphocytes is unclear [202]. It has been speculated that the interaction of beryllium with proteins, perhaps on the surface of macrophages, produces neoantigens responsible for the disease.

\section{Cobalt-induced Lung Disease}

Cobalt is used in so-called hard metal where it is used to alloy tungsten carbide and sometimes other metals to given an exceptionally hard metal used for grinding drill tips and tool edges. Workers using hard metal are at risk for industrial asthma and for infiltrative lung disease $[203,204]$. Both are uncommon and probably represent hypersensitivity reactions rather than dose-related toxicity. The pathology of the infiltrative lung disease in its early or active phase consists of patchy interstitial infiltrates of mononuclear cells accompanied by hyperplasia of the alveolar lining epithelium and extensive accumulation of macrophages within the alveolar spaces. A distinctive feature is the presence of numerous intra-alveolar multinucleated giant cells with numerous nuclei and often exhibiting 'cannibalism', that is seeming to engulf other mononuclear macrophages. Electron microscopy suggests that some giant cells may be of epithelial origin [204] although the large majority are macrophages and stain immunohistochemically with the macrophage marker CD68. It is currently thought that most of the patients described by Liebow in the 1960 s as giant cell interstitial pneumonia are examples of hard metal disease. In its late stages the infiltrative lung disease may show only non-specific fibrosis.

Most evidence indicates that cobalt rather than tungsten carbide is the pathogenic component of hard metal. This conclusion is supported by animal experiments and by the occurrence of identical interstitial pneumonia in diamond polishers who were exposed to cobalt but not tungsten carbide [205]. Inhalation challenge in asthmatic patients has shown positive response to cobalt [206].

\section{Proliferative Lesions Causing Diffuse Lung Disease}

\author{
Langerhans' Cell Granulomatosis
}

The Langerhans' cell is a poorly phagocytic specialized antigen-presenting cell of bone marrow origin which populates squamous epithelium [207]. In the lung these cells can be found in the epithelium of small airways and increase in number in smokers, perhaps stimulated by antigens in tobacco smoke [208]. Langerhans' cell granulomatosis has a very different course and natural history depending on patient age [209,210]. In children less than two years of age it is an aggressive systemic disease which usually involves the skin and reticuloendothelial system and sometimes involves the lung where it can cause severe honeycombing. In contrast, the disease in adults is usually limited to a single organ, typically bone or lung, and evolves slowly. Its course in older children is intermediate in severity. Langerhans' cell granulomatosis has been placed here among proliferative lesions based in part on the behavior of the pediatric variants and in part because even in adults all the lesions examined have been clonal $[211,212]$. They were derived from bone, however, not lung and some authorities favor a cytokine-driven inflammatory or immune reaction [213].

Pulmonary Langerhans' cell granulomatosis usually occurs in young adults and nearly all are smokers. The lesions are discrete nodules varying in size from millimeters to one or two centimeters. They tend to spare the basilar portions of the lung. They occasionally cavitate and can cause cyst formation leading to pneumothorax. Microscopically, early lesions are nodular collections of Langerhans' cells in the interstitium accompanied by small numbers of neutrophils, lymphocytes and siderophages $[214,215]$. Eosinophils can be plentiful, accounting for the older term eosinophilic granuloma, but may also be absent. The Langerhans' cells have a characteristic microscopic appearance with highly folded nuclei and moderate amounts of amphophilic cytoplasm (Figure 1.22). Their identity can be confirmed by electron microscopic demonstration of their unique cytoplasmic organelles, Birbeck granules, or by the use of immunologic markers among which only antisera to S- 100 protein and CD1a are widely available. The lesions may heal spontaneously or in response to therapy or they may evolve into poorly cellular fibrous scars that often have a stellate configuration. Consequently, most patients improve or stabilize; progression to honeycomb lung occurs in a small minority. 


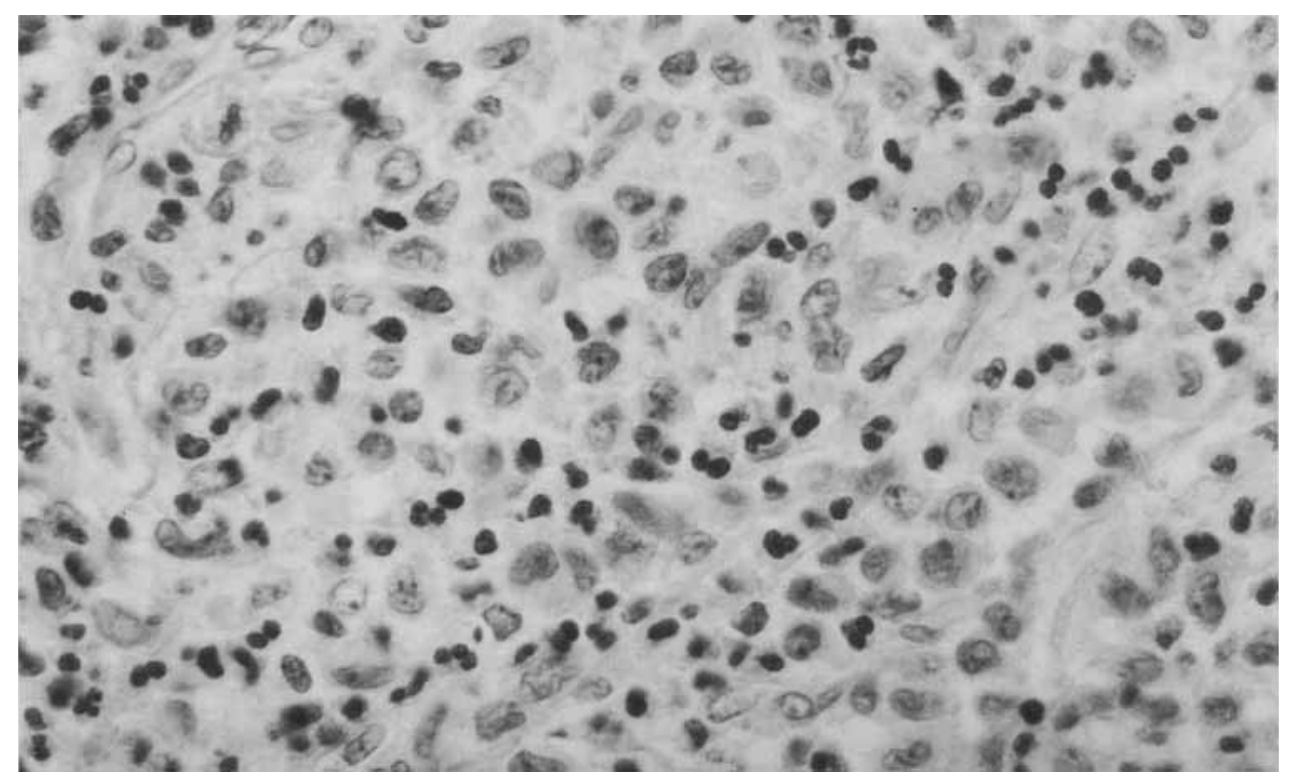

Figure 1.22. Langerhans cell granulomatosis with a mixture of eosinophils with dark bilobed nuclei and larger Langerhans cell with notched and folded nuclei with open chromatin.

\section{Lymphangioleiomyomatosis}

Lymphangioleiomyomatosis is virtually limited to premenopausal women. The basic pathology is a proliferation of immature smooth muscle cells which begins in the pleura and around bronchovascular structures where there are lymphatics but extends to involve walls of alveoli as well $[216,217]$. Inflammation is minimal or absent. The proliferating cells closely resemble smooth muscle and indeed react with antibodies to the standard smooth muscle markers alpha actin and desmin. Surprisingly they may also contain premelanosomes by electron microscopy and often react with antibodies to the premelanosome protein HMB-45 [218].

The clinical picture of lymphangioleiomyomatosis is distinctive [217]. Whereas the lung shrinks in infiltrative lung disease with fibrosis and honeycombing, in lymphangioleiomyomatosis the lung is enlarged with cysts of unusually uniform size [219]. Hemoptysis, pneumothorax, and chylous effusion are common, because the proliferating cells obstruct veins, airways and lymphatics.

Because of the enormous preponderance of women of child-bearing age and reports of clinical deterioration during pregnancy or estrogen therapy, some have proposed that lymphangioleiomyomatosis may be hormonally sensitive. The disease is sufficiently rare that the efficacy of hormonal therapy is controversial [220]. The determination of estrogen and progesterone receptors in biopsies has not proven useful and appears to reflect the time during the menstrual cycle that the tissue is obtained. Currently, the preferred therapy is lung transplantation, but a few examples of recurrence of the disease in the allograft have been reported [221].

Lung lesions in patients with tuberous sclerosis may be identical to those of lymphangioleiomyomatosis. The relation of the two diseases is unclear, but both are often associated with benign renal tumors, angiomyolipomas.

\section{Lymphoproliferative lesions}

The lung is a major lymphoid organ with IgAproducing plasma cells diffusely scattered through the bronchi and grouped around mucus glands and with organized lymphoid nodules in association with bronchioles, respiratory bronchioles, and perilobular septa. These lymphoid tissues can undergo reactive hyperplasia in inflammatory disease and can give rise to malignant lymphomas. Follicular bronchitis and bronchiolitis is a reactive hyperplasia of the peribronchial and septal-pleural lymphoid tissues with the development of germinal centers. It occurs in collagen-vascular disease, especially rheumatoid disease, and in some immunodeficiency states [222]. Similar lymphoid hyperplasia occurs in bronchiectasis. Pseudolymphomas are lymphocyte rich inflammatory pseudotumors [223]. They are rare and usually present as asymptomatic single mass lesions in the lung parenchyma, but they can 
be multiple, especially in the setting of Sjögren's syndrome. They are characterized by numerous germinal centers and often have abundant plasma cells and show evidence of fibrosis. They resemble some low grade lymphomas and indeed low grade lymphomas have often been incorrectly called pseudolymphomas, but if marker studies are done there is no evidence of clonality in the proliferating cells of pseudolymphoma [224]. In lymphocytic interstitial pneumonia there is widespread infiltration of the alveolar septa as well as perilobular septa by lymphocytes and mature plasma cells. Germinal centers may be present. Patients usually have respiratory symptoms including cough and dyspnea and the chest radiograph shows bibasilar reticulonodular infiltrates. Either hyperglobulinemia or hypoglobulinemia can be associated with lymphocytic interstitial pneumonia [225].

Lymphocytic interstitial pneumonia may be a manifestation of autoimmune disease, such as Sjögren's syndrome or primary biliary cirrhosis. It is a well established complication of HIV infection where it is disproportionately common in children [226,227]. In some instances, infiltration of major and minor salivary glands by $C D-8$ positive lymphocytes can accompany lymphocytic interstitial pneumonia in those with HIV [228].

Epstein-Barr virus has been demonstrated in some cases of lymphocyte interstitial pneumonia in both HIV-infected and uninfected subjects. Its exact role is unclear. In one study the viral antigen was found in epithelial cells and was absent from the lymphocytes [229]. In Japan, where human T-cell lymphocytotropic virus is endemic, it may have a role in the etiology of LIP.

Most malignant lymphomas of the lung are low grade B-cell lymphomas and are thought to arise from the mucosa-associated lymphoid tissue $[224,225,230,231]$. They usually present as a single or multiple nodules composed of a uniform population of relatively mature lymphocytes. At the periphery of the nodules these cells extend along the lymphatics accompanying the bronchovascular structures. Lymphoepithelial complexes are typical but are not always present. In some cases a few germinal centers or non-caseating granulomas may suggest a reactive process and immunologic or genetic evidence of clonality is required for diagnosis. The course of low grade pulmonary lymphomas is protracted and therapy can be curative in as much as $50 \%$ of patients. Even in those subjects in whom the lymphoma recurs long survival is the rule.

High grade lymphomas can arise de novo or evolve from a well differentiated lymphoma. They usually form one or several mass lesions. Patients are usually symptomatic and often have involve- ment of other sites. Survival at 5 years is reported to be $0 \%-60 \%[230,231]$. Hodgkin's disease can also involve the lung.

The lesion originally described under the name lymphomatoid granulomatosis is now accepted as a variant of angiocentric malignant lymphoma [232]. Morphologic features are a polymorphic infiltrate which includes some large atypical lymphoid cells, invasion of blood vessels by the infiltrate and areas of geographic necrosis. Patients have respiratory symptoms often accompanied by systemic symptoms of fever and weight loss. Extrapulmonary lesions occur, usually in the skin or brain. Chest radiography shows multiple large mass-like lesions which sometimes cavitate. The available evidence indicates that some cases are of B-cell origin and some T-cell; many contain Epstein-Barr virus mRNA in the malignant lymphoid cells, but probably not all [233].

\section{Epithelioid Hemangioendothelioma}

Epithelioid hemangioendothelioma is an uncommon tumor which can arise in a number of sites including the lung. In lung this tumor usually manifests itself as multiple bilateral nodules, usually a centimeter or less in diameter. The course is variable, but may be quite protracted and some patients live for as long as 10 years before dying of respiratory failure [234].

The morphology of the lesions is distinctive. Growth occurs mainly within airspaces. At the periphery the lesions show plump cells sloughing into alveoli. In the center, the lesions can be sclerotic and poorly cellular. In the transition, the cells grow in branching chains and produce an abundant myxoid stroma that resembles cartilage matrix which fills the airspaces. Electron microscopy and factor VIII staining have established the identity of the tumor cells as endothelium.

\section{Epithelial Lesions}

Of the primary lung cancers, only bronchioloalveolar carcinoma (BAC) can cause diffuse lung disease. $B A C$ is characterized by its lepidic growth pattern, i.e. by growth of the neoplastic epithelial cells along the pre-existing alveolar walls which serve as the stroma. It is this growth pattern rather than the differentiation of the tumor cells which defines the tumor. The tumor cells may display features of bronchial mucus-secreting goblet cells, bronchiolar Clara cells, or type II alveolar cells [235]. As a rule the mucus-secreting cells grow along normal alveolar septa while the secreted mucus fills the air spaces. In non-mucus secreting tumors the Clara 
cells or type II cells grow along alveolar walls that show fibrous thickening and some mononuclear infiltration [236].

Three gross and radiographic patterns of $\mathrm{BAC}$ are recognized: Tumors that form a single peripheral mass and the two patterns that cause diffuse lung disease: multifocal pneumonic consolidation with air bronchograms and multiple bilateral pulmonary nodules. The latter two patterns occur more often when the tumor cells are of the mucus-secreting type, although non-mucinous $\mathrm{BAC}$ can also give these patterns. The mucinous BAC is the cellular type responsible for two very rare clinical presentations: mucinous bronchorrhea and hypoxemia caused by shunt resulting from perfusion of involved lung in which the alveoli are filled with mucus and cells.

Recent studies indicate that the incidence of BAC is increasing, particularly in young non-smoking women [236]. Although some studies show that $\mathrm{BAC}$ has a more favorable prognosis than other adenocarcinoma, this obviously does not apply to those $\mathrm{BAC}$ causing diffuse lung disease which are invariably fatal.

The carcinoid tumorlet is a benign proliferation of neuroendocrine cells either in bronchioles or in bronchiectatic large bronchi. Despite some histologic resemblance to carcinoids and small cell carcinoma, tumorlets are virtually always benign and are usually microscopic findings of no clinical importance. Recently, multiple tumorlets in small airways have been recognized as a rare cause of diffuse obstructive lung disease $[237,238]$. It is unknown whether the obstruction is caused by proliferating epithelial cells filling the airway lumen or whether the tumor cells produce fibrogenic factors causing airway fibrosis.

\section{Metastatic Tumors}

Metastatic tumors are the commonest tumors in the lung. Clinical presentation varies. Hematogenous metastases are common in sarcomas, testicular tumors, and carcinomas of the colon, kidney and breast, and usually cause multiple nodules or masses in the lung parenchyma. Some mucinous tumors metastasize with a growth pattern indistinguishable from bronchioloalveolar carcinoma, save for the presence of an evident extrapulmonary primary. Endobronchial metastases can occur and mimic primary carcinomas. Lymphangiitic carcinoma can mimic interstitial lung disease causing bilateral reticulonodular infiltrates on chest radiographs and restriction of ventilation [239]. Microscopically, tumor cells are seen distending the peribronchial, perivascular and pleural lymphatics. Tumor cells are usually also present in the lumens of some small arteries and some authorities believe that lymphangiitic involvement is usually a secondary change and that intravascular tumor cells traverse the vessel wall to reach perivascular lymphatics. Lymphangiitic carcinoma is most common with primary tumors of the breast, stomach and pancreas.

\section{References}

1. Lymphany PA, duBois RM (1987) Diffuse lung disease: product of genetic susceptibility and environmental encounters. Thorax 52:92-94.

2. Kuhn C, Pierce JA (1991) Lung repair in COPD. In: Cherniak NS, ed. Chronic obstructive pulmonary disease. WB Saunders, Philadelphia, pp. 49-55.

3. Hogg JC, Macklem PT, Thurlbeck WM (1968) Site and nature of airway obstruction in chronic obstructive lung disease. N Engl J Med 278:1355-1360.

4. Jeffrey P (1991) Morphology of the airway wall in asthma and in chronic obstructive pulmonary disease. Am Rev Respir Dis 143:1152-1158.

5. Ohashi Y, Motogima S, Fukuda T et al. (1992) Airway hyperresponsiveness increased intercellular spaces of bronchial epithelium and increased infiltration of eosinophils and lymphocytes in bronchial mucosa in asthma. Am Rev Respir Dis 144:1469-1476.

6. Laitinen LA, Heino M, Laitinen A et al. (1985) Damage of the airway epithelium and bronchial reactivity in patients with asthma. Am Rev Respir Dis 131:599-600.

7. Takizawa T, Thurlbeck WM (1971) Muscle and mucous gland size in the major bronchi of patients with chronic bronchitis, asthma and asthmatic bronchitis. Am Rev Resp Dis 104:331-336.

8. Sobonya RE (1984) Quantitative structural alterations in longstanding allergic asthma. Am Rev Resp Dis 130:289-292.

9. Azzawi M, Johnston PW, Majumdar et al. (1992) T-lymphocytes and activated eosinophils in airway mucosa in fatal asthma and cystic fibrosis. Am Rev Respir Dis 145:1477-1482.

10. Robinson D, Homid Q, Ying $S$ et al. (1992) Predominant $\mathrm{TH}_{2}$-like, bronchoalveolar T-lymphocyte population in atopic asthma. $\mathrm{N}$ Engl J Med 326:298-304.

11. Barnes PJ, Baraniuk J, Belvisi MG (1991) Neuropeptides in the respiratory tract. Am Rev Respir Dis 144:1187-1198.

12. Kuwano K, Bosken CH, Pare PD et al. (1993) Small airway dimensions in asthma and in chronic obstructive pulmonary disease. Am Rev Respir Dis 148:1220-1225.

13. Wiggs BR, Bosken CH, Pare PD et al. (1992) A model of airway narrowing in asthma and in 
chronic obstructive pulmonary disease. Am Rev Respir Dis 145:1251-1258.

14. Whitwell F (1952) A study of the pathology and pathogenesis of bronchiectasis. Thorax 7:213-239.

15. Barker AF, Bardana EJ (1988) Bronchiectasis: Update of an orphan disease. Am Rev Respir Dis 137:969-978.

16. Mierau GW, Agostini R, Beals TF et al. (1992) The role of electron microscopy in evaluating ciliary dysfunction: report of a workshop. Ultrastruct Pathol 16:245-254.

17. Davis PB, Drumm M, Konstan MW (1996) Cystic fibrosis. Am J Respir Crit Care Med 154:1229-1256.

18. Al-Awqati Q (1995) Regulation of ion channels by ABC transporters that secrete ATP. Science 269:805-806.

19. Higgins CF (1995) The ABC of channel regulation. Cell 82:693-696.

20. Ismailou IL, Awayda MS, Jovov B et al. (1996) Regulation of epithelial sodium channels by the cystic fibrosis transmembrane conductance regulator. J Biol Chem 271:4725-4732.

21. Kopito RR (1997) ER quality control: the cytoplasmic connection. Cell 88:427-430.

22. Smith Jf, Travis SM, Greenberg EP et al. (1996) Cystic fibrosis airway epithelia fail to kill bacteria because of abnormal airway surface fluid. Cell 85:229-236.

23. Goldman MJ, Anderson GM, Stolzenberg ED et al. (1997) Human B-defensin is a salt sensitive antibiotic in lung that is inactivated in cystic fibrosis. Cell 88:553-560.

24. Barasch J, Kiss B, Prince A et al. (1991) Defective acidification of intracellular organelles in cystic fibrosis. Nature 352:70-73.

25. Debentzmann S, Roger P, Puchelle E (1996) Pseudomonas aeruginosa adherence to remodelling respiratory epithelia. Eur Respir J 9:2145-2150.

26. Bedard M, McClure CD, Schiller NL (1993) Release of interleukin 8 , interleukin 6 and colony stimulating factor by upper airway epithelial cells. Implications for cystic fibrosis. Am J Resp Cell Mol Biol 9:455-462.

27. Greenberger PA, Patterson R (1987) Allergic bronchopulmonary aspergillosis. Model of bronchopulmonary disease with defined serologic, radiologic, pathologic and clinical findings from asthma to fatal destructive lung disease. Chest 91:165S-170S.

28. Bosken C, Myers J, Greenberger P et al. (1988) Pathologic features of allergic bronchopulmonary aspergillosis. Am J Surg Pathol 12:216-222.

29. Koss MN, Robinson RG, Hochlolzer L (1981) Bronchocentric granulomatosis. Human Pathol 12:632-639.

30. Wright SL, Cagle P, Churg A et al. (1992) Diseases of the small airways. Am Rev Respir Dis 146:240-262.

31. Saetta M, Finkelstein M, Cosio MG (1994) Morphologic and cellular basis for airflow limitation in smokers. Eur Respir J 7:1505-1515.

32. Hogg JC, Wright JL, Wiggs BR et al. (1994) Lung structure and function in cigarette smokers. Thorax 49:473-478.
33. Thurlbeck WM (1991) Pathology chronic airflow obstruction. In: Cherniack NS, ed. Chronic obstructive pulmonary disease. WB Saunders, Philadelphia, pp. 3-20.

34. Silverman EK, Pierce JA, Province MA et al. (1989) Variability of pulmonary function in alpha-1-antitrypsin deficiency: Clinical correlates. Ann Intern Med 111:982-991.

35. Matsuse T, Hayaski S, Kuwano K et al. (1992) Latent adenoviral infection in the pathogenesis of chronic airways obstruction. Am Rev Respir Dis 146:177-184.

36. King TE (1989) Bronchiolitis obliterans. Lung 167:69-93.

37. Turton CW, Williams G, Green M (1981) Cryptogenic obliterative bronchiolitis in adults. Thorax 36:805-810.

38. Yousem SA, Colby TV, Carrington CB (1985) Follicular bronchitis/bronchiolitis. Human Pathol 16:700-706.

39. Kraft M, Mortenson RL, Colby TL et al. (1993) Cryptogenic constrictive bronchiolitis. A clinicopathologic study. Am Rev Respir Dis 148:1093-1101.

40. Sugiyama Y (1993) Diffuse panbronchiolitis. Clin Chest Med 14 (4): 765-772.

41. Iwata M, Colby TV, Kitaichi M (1994) Diffuse panbronchiolitis. Diagnosis and distinction from various pulmonary diseases with centrilobular interstitial foam cell accumulations. Hum Pathol 25:357-363.

42. Carlson BA, Swenson SJ, Edell ES et al. (1993) High resolution computed tomography for obliterative bronchilitis. Mayo Clin Proc 68:307-308.

43. Wilson TA, Bachofen H (1982) A model for mechanical structure of the alveolar duct. J Appl Physiol 52:1064-1070.

44. Kuhn C (1996) Morphology of the aging lung. In: Crystal RG, West JB, Weibel ER, Barnes PJ, eds. The Lung. Scientific Foundations. 2nd ed. Lippincott-Raven, Philadelphia and New York, pp. 2187-2197.

45. Snider GL, Kleinerman J, Thurlbeck WM et al. (1985) The definition of emphysema. A report of a National Heart, Lung and Blood Institute, Division of Lung Disease Workshop. Am Rev Respir Dis 132:182-185.

46. Janoff A (1985) Elastases and emphysema. Current assessment of the protease-antiprotease hypothesis. Am Rev Respir Dis 132:417-433.

47. Snider GL (1992) Emphysema: The first two centuries and beyond. A historical overview with suggestions for future research. Am Rev Respir Dis 146:1334-1344 and 1615-1622.

48. Erikson S (1989) Alpha-antitrypsin deficiency: Lesson learned from the bedside to the gene and back again. Chest 95:181-189.

49. Weitz JL, Silverman EK, Thong B et al. (1991) Plasma levels of elastase-specific fibrinopeptides correlate with protease inhibitor phenotype. J Clin Invest 88:766-773.

50. Tetley TD (1997) Matrix metalloproteinases: a role in emphysema? Thorax 52:495. 
51. Finlay GA, Russell KJ, McMahon KS et al. (1997) Elevated levels of matrix metalloproteinases in bronchoalveolar lavage fluid of emphysematous patients. Thorax 52:502-506.

52. Evans MD, Pryor WA (1994) Cigarette smoking, emphysema, and damage to alpha (1)-proteinase inhibitor. Am J Physiol 226:L593-L611.

53. Hogg JC (1992) Chronic interstitial disease of unknown cause. A new classification based on pathogenesis. AJR 156:225-233.

54. Tomashefski JR (1990) Pulmonary pathology of the adult respiratory distress syndrome. Clin Chest Med 11:593-619.

55. Bertozzi P, Astedt B, Zenius L et al. (1990) Depressed bronchoalveolar urokinase activity in patients with adult respiratory distress syndrome. N Engl J Med 322:890-897.

56. Idell S, James KK, Levin EG et al. (1989) Local abnormalities in coagulation and fibrinolytic pathways predispose to alveolar fibrin deposition in the adult respiratory distress syndrome. J Clin Invest 84:695-705.

57. Eitzman DT, McCoy RD, Zheng X et al. (1996) Bleomycin-induced pulmonary fibrosis in transgenic mice that either lack or overexpress the murine plasminogen activator inhibitor-1 gene. J Clin Invest 97:232-237.

58. Yano T, Deterding RR, Simonet WS et al. (1996) Keratinocyte growth factor reduces lung damage due to acid instillation in rats. Am J Respir Cell Mol Biol 15:433-442.

59. Askin FB (1990) Back to the future: The HammanRich Syndrome and acute interstitial pneumonia. Mayo Clin Proc 65:1624-1626.

60. Olson J, Colby TV, Elliott CG (1990) Hamman-Rich Syndrome revisited. Mayo Clin Proc 65:1538-1548.

61. Colby TV (1992) Pathologic aspects of bronchiolitis obliterans organizing pneumonia. Chest 102 Suppl: $38 \mathrm{~S}-43 \mathrm{~S}$.

62. Kitaichi M (1992) Differential diagnosis of bronchiolitis obliterans organizing pneumonia. Chest 102 Suppl: 44 S-49S.

63. Davidson AG, Heard BE, McAllister WAC et al. (1983) Cryptogenic organizing pneumonitis. Quart. J Med 52:383-394.

64. Epler GR, Colby TV, McLoud TC et al. (1985) Bronchiolitis obliterans organizing pneumonia. N Engl J Med 312:152-158.

65. Belloma R, Finlay M, McLaughlin P et al. (1991) Clinical spectrum of cryptogenic organizing pneumonitis. Thorax 46:554-558.

66. Katzenstein ALA (1993) Idiopathic interstitial pneumonia: classification and diagnosis. In: Churg A, Katzenstein ALA, eds. The lung. Current concepts. Williams and Wilkins, Baltimore, pp. 1-31.

67. Corrin B, Dewar A, Rodriquez et al. (1985) Fine structural changes in cryptogenic fibrosing alveolitis and asbestosis. J Pathol 147:107-119.

68. Myers JL, Katzenstein ALA (1988) Epithelial necrosis and alveolar collapse in the pathogenesis of usual interstitial pneumonia. Chest 94:1309-1311.
69. Burkhardt A (1986) Pathogenesis of pulmonary fibrosis. Human Pathol 17:971-973.

70. Basset F, Ferrans VS, Soler et al. (1986) Intraluminal fibrosis in interstitial lung disorders. Am J Pathol 122:443-461.

71. Kuhn C, Boldt J, King TE et al. (1989) An immunohistochemical study of architectural remodeling and connective tissue synthesis in pulmonary fibrosis. Am Rev Respir Dis 140:1693-1703.

72. Hubbard R, Lewis S, Richards K et al. (1996) Occupational exposure to metal or wood dust and etiology of cryptogenic fibrosing alveolitis. Lancet 347:284-289.

73. Egan JJ, Woodcock AA, Stewart JP (1997) Viruses and idiopathic pulmonary fibrosis. Eur Respir J 10:1433-1437.

74. duBois RM (1991) Recent advances in the immunology of interstitial lung disease. Clin Exp Allergy 21:9-16.

75. Kradin RL, Divertie MB, Colvin RB et al. (1986) Usual interstitial pneumonitis is a T-cell alveolitis. Clin Immunol Immunopathol 40:224-235.

76. Campbell DA, Poulter LW, Janossy G et al. (1985) Immunohistological analaysis of lung tissue from patients with cryptogenic fibrosing alveolitis suggesting local expression of immune hypersensitivity. Thorax 40:405-411.

77. Kallenberg CGM, Schilizzi BM, Beaumont F et al. (1987) Expression of class II major histocompatibility complex antigens on alveolar epithelium in interstitial lung disease: relevance to pathogenesis of idiopathic pulmonary fibrosis. J Clin Pathol 40:725-733.

78. Wallace WAH, Schofield JA, Lamb D et al. (1994) Localization of a pulmonary autoantigen in cryptogenic fibrosing alveolitis. Thorax 49:1139-1145.

79. Wallace WAH, Roberts SN, Caldwell H et al. (1994) Circulating antibodies to lung proteins in patients with cryptogenic fibrosing alveolitis. Thorax 49:218-224.

80. Gauldie J, Jordana M, Cox G (1993) Cytokines and pulmonary fibrosis. Thorax 48:931-935.

81. Suganuma H, Soto A, Tamura R et al. (1995) Enhanced migration of fibroblasts derived from lungs with fibrotic lesions. Thorax 50:987-989.

82. Torry DJ, Richards CD, Podor TS et al. (1994) Anchorage-independent colony growth of pulmonary fibroblasts derived from fibrotic human lung tissue. J Clin Invest 93:1525-1532.

83. Liebow AA, Steer A, Billingsley JG (1965) Desquamative interstitial pneumonia. Am J Med 39:369-404.

84. Carrington CB, Gaensler EA, Coutu RE et al. (1978) Natural history and treated course of usual and desquamative interstitial pneumonia. $\mathrm{N}$ Engl J Med 298:801-809.

85. Hartman TE, Primack SL, Swenson SJ et al. (1993) Desquamative interstitial pneumonia: Thin-section CT findings in 22 patients. Radiology 187:787-790.

86. Katzenstein ALA, Fiorelli RF (1994) Non-specific interstitial pneumonia/fibrosis. Histologic features 
and clinical significance. Am J Surg Pathol 18:136-147.

87. Mitchell DN, Scadding JG (1974) State of the art. Sarcoidosis $110: 774-802$.

88. Almenoff PL, Johnson A, Lesser M et al. (1996) Growth of acid fast L-forms from the blood of patients with sarcoidosis. Thorax 51:530-533.

89. Kon OM, duBois RM (1997) Mycobacteria and sarcoidosis. Thorax 52 (Suppl 3):547-553.

90. Mitchell IC, Turk SL, Mitchell DN (1992) Detection of mycobacterial DNA in sarcoidosis with liquid phase hybridization. Lancet 339:1015-1017.

91. Saboor SA, Johnson NM, McFadden J (1992) Detection of mycobacterial DNA in sarcoidosis and tuberculosis with polymerase chain reaction. Lancet 339:1012-1015.

92. Popper HH, Winter E, Hofler G (1994) DNA of mycobacterium tuberculosis and sarcoidosis detected by polymerase chain reaction. Am J Clin Pathol 101:738-741.

93. Ghussein RA, Ross DG, Salomon RN et al. (1994) A search for mycobacterial DNA in sarcoidosis using the polymerase chain reaction. Am J Clin Pathol 101:733-737.

94. Hsu RM, Connors AF, Tomashefski JF (1996) Histologic, microbiologic and clinical correlates of the diagnosis of sarcoidosis by transbronchial biopsy. Arch Pathol Lab Med 120:364-368.

95. Kaltreider HB (1993) Hypersensitivity pneumonitis. West J Med 159:570-578.

96. Keller RH, Calvanico NJ, Stevens JO (1982) Hypersensitivity pneumonitis in nonhuman primates. Studies on the relationship of immunoregulation and disease activity. J Immunol 128:116-122.

97. Reyes CN, Wenzel FS, Lawton BR et al. (1982) The pulmonary pathology of farmer's lung disease. Chest 81:142-146.

98. Hammar S (1988) Hypersensitivity pneumonitis. Pathol Annual 23:193-215.

99. Sneller MC (1995) Wegener's granulomatosis. JAMA 273:1288-1291.

100. DeRemee RA, McDonald TS, Harrison EG et al. (1976) Wegener's granulomatosis: anatomic correlates, a proposed classification. Mayo Clin Proc 51:777-781.

101. Gephardt GN, Shah LF, Tubbs RR et al. (1990) Wegener's granulomatosis. Immunomicroscopic and ultrastructural study of four cases. Arch Pathol Lab Med 114:961-965.

102. Schultz DR, Tozman EC (1995) Antineutrophil cytoplasmic antibodies with major antigens, pathophysiology and disease associations. Semin Arthritis Rheum 25:143-159.

103. Colby TV, Specks U (1993) Wegener's granulomatosis in the 1990s. A pulmonary pathologists perspective. In: Churg A, Katzenstein ALA, eds. The lung. Current concepts. Williams and Wilkins Co., Baltimore, pp. 195-218.

104. Travis WD, Hoffman GS, Leavitt RY et al. (1991) Surgical pathology of the lung in Wegener's granulomatosis. Review of 87 open lung biopsies from 67 patients. Am J Surg Pathol 15:315-333.

105. Yousem SA (1991) Bronchocentric injury in Wegener's granulomatosis. Human Pathol 22:535-540.

106. Yousem SA (1988) The eosinophilic variant of Wegener's granulomatosis. Human Pathol 19:682-688.

107. Uner AH, Rozum-Sloter B, Katzenstein ALA (1996) Bronchiolitis obliterans-organizing pneumonia (BOOP)-like variant of Wegener's granulomatosis. A clinicopathologic study of 16 cases. Am J Surg Pathol 20:794-801.

108. Lanham JG, Elkon KB, Pusey CD et al. (1984) Systemic vasculitis with asthma and eosinophilia: a clinical approach to the Churg-Strauss syndrome. Medicine 63:65-81.

109. Koss MN, Antonovych T, Hockholzer L (1981) Allergic granulomatosis (Churg-Strauss syndrome): pulmonary and renal morphologic findings. Am J Surg Pathol 5:21-28.

110. Yousem SA, Colby TV, Carrington CB (1985) Lung biopsy in rheumatoid arthiritis. Am Rev Respir Dis 131:770-777.

111. Allen SA, Davis WB (1994) Eosinophilic lung diseases. Am J Respir Crit Care Med 150:1423-1438.

112. Liebow AA, Carrington CB (1969) The eosinophilic pneumonias. Medicine 48:251-285.

113. Bartler T, Irwin RS, Nash G et al. (1989) Idiopathic bronchiolitis obliterans-organizing pneumonia with peripheral infiltrates on chest roentgenogram. Arch Intern Med 149:273-279.

114. Bodesch DB, King TE, Schwartz MI (1989) Acute eosinophilic pneumonia: a hypersensitivity phenomenon? Am Rev Respir Dis 139:249-252.

115. Pope-Harman RL, Davis WB, Allen ED et al. (1996) Acute eosinophilic pneumonia. A summary of 15 cases and review of the literature. Medicine 75:334-342.

116. Carrington $\mathrm{CB}$, Addington WW, Goff $\mathrm{AM}$ et al. (1969) Chronic eosinophilic pneumonia. N Engl J Med 180:786-798.

117. Jederlinc PJ, Sicilian L, Gaensler EA (1988) Chronic eosinophilic pneumonia. A report of 19 cases and a review of the literature. Medicine 67:154-162.

118. Ottesen EA, Nutman TB (1992) Tropical pulmonary eosinophilia. Ann Rev Med 43:417-424.

119. Udwadia FE (1993) Tropical eosinophilia: a review. Respir Med 87:17-21.

120. Robbins RA, Linder J, Stahl MG et al. (1989) Diffuse pulmonary hemorrhage in autologous bone marrow transplant recipients. Am J Med 87:511-518.

121. Chao N, Duncan SR, Long GD et al. (1991) Corticosteroid therapy for diffuse alveolar hemorrhage in autologous bone marrow transplant recipients. Ann Intern Med 114:145-146.

122. Travis WD, Colby TV, Lombard C et al. (1990) A clinicopathologic study of 34 cases of diffuse pulmonary hemorrhage with lung biopsy confirmation. Am J Surg Pathol 14:1112-1125.

123. Green RJ, Ruoss SJ, Kraft SA et al. (1996) Pulmonary capillaritis and alveolar hemorrhage. 
Update on diagnosis and management. Chest 110:1305-1316.

124. Mark EJ, Ramirez JF (1985) Pulmonary capillaritis and hemorrhage with systemic vasculitis. Arch Pathol Lab Med 109:413-418.

125. Travis WD, Carpenter HA, Lie ST (1987) Diffuse pulmonary hemorrhage. An uncommon manifestation of Wegener's granulomatosis. Am J Surg Pathol 11:702-708.

126. Lombard CM, Colby TV, Elliott CG (1989) Surgical pathology of the lung in antibasement-membrane antibody-associated Goodpasture's Syndrome. Human Pathol 20:445-451.

127. Kelly PT, Hapovik EF (1994) Goodpasture's syndrome: Molecular and clinical advances. Medicine 73:171-185.

128. Hellmark T, Johansson C, Wieslander J (1994) Characterization of anti GBM antibodies involved in Goodpasture's syndrome. Kidney International 46:823-829.

129. Blanco A, Solis P, Gomez S et al. (1994) Anti neutrophil cytoplasmic antibodies in idiopathic pulmonary hemosiderosis. Pediat Allergy Immunol 5:235-239.

130. Rosen SH, Castleman B, Liebow AA (1958) Pulmonary alveolar proteinosis. N Eng J Med 258:1123-1142.

131. Kuhn C, Gyorkey F, Levine BE et al. (1966) Pulmonary alveolar proteinosis. Lab Investigation 15:492-509.

132. Godwin JD, Muller NL, Takasugi JE (1988) Pulmonary alveolar proteinosis: CT findings. Radiology 169:609-613.

133. Buechner HA, Ansari A (1969) Acute silicoproteinosis. A new pathologic variant of acute silicosis in sandblasters characterized by histologic features resembling alveolar proteinosis. Dis Chest 44:274-284.

134. Bedrossian CMW, Luna MA, Conklin RH et al. (1980) Alveolar proteinosis as a consequence of immunosuppression. A hypothesis based on clinical and pathologic observations. Human Pathol 11:527-534.

135. Ruben FL, Talamo TS (1986) Secondary pulmonary alveolar proteinosis occurring in two patients with acquired immune deficiency syndrome. Am J Med $80: 1187-1190$.

136. Singh G, Katyal SL, Bedrossian CMW et al. (1983) Pulmonary alveolar proteinosis: staining for surfactant apoprotein in alveolar proteinosis and in conditions simulating it. Chest 83:82-86.

137. Nogee LM, deMello DE, Dehner LP et al. (1993) Deficiency of pulmonary surfactant protein $B$ in congenital alveolar proteinosis. $N$ Engl J Med 328:406-410.

138. Nogee LM, Garnier G, Dietz HC et al. (1994) A mutation in the surfactant protein $B$ gene responsible for fatal neonatal respiratory disease in multiple kindreds. J Clin Invest 93:1860-1863.

139. Heppleston AG, Fletcher K, Wyatt I (1974) Changes in the composition of lung lipids and the turnover of dipalmitoyl lecithin in experimental alveolar lipo-proteinosis induced by inhalation of quartz. $\mathrm{Br}$ J Exp Pathol 55:384-394.

140. Ikegami M, Ueda T, Hull W et al. (1996) Surfactant metabolism in transgenic mice after granulocytemacrophage colony stimulating factor ablation. Am J Physiol 270 (Lung Cell Mol Physiol 14): L650-L658.

141. Witty LA, Tapson VF, Piantadosi CA (1994) Isolation of mycobacteria in patients with pulmonary alveolar proteinosis. Medicine 73:103-109.

142. Golde DW, Territo M, Finley TN et al. (1976) Defective lung macrophages in pulmonary alveolar proteinosis. Ann Intern Med 85:304-309.

143. Conger JD, Hammond WS, Alfrey AC et al. (1975) Pulmonary calcification in chronic dialysis patients. Clinical and pathologic studies. Ann Intern Med 83:330-336.

144. Grames GM, Sauser DD, Jansen C et al. (1974) Radionucleide detection of diffuse interstitial pulmonary calcification. JAMA 230:992-995.

145. Popelka CG, Kleinerman J (1977) Diffuse pulmonary ossification. Arch Intern Med 137:523-525.

146. Sears MR, Chang AF, Taylor AJ (1971) Pulmonary alveolar microlithiasis. Thorax 26:704-711.

147. Prakash LB, Barham SS, Rosenow EC et al. (1983) Pulmonary alveolar microlithiasis. A review including ultrastructural and pulmonary function studies. Mayo Clin Proc 58:290-300.

148. Chen KTK (1989) Amyloidosis presenting in the respiratory tract. Pathol Ann 24 pt 1:253-274.

149. Utz JP, Swenson SJ, Gertz MA (1996) Pulmonary amyloidosis: The Mayo Clinic experience from 1980-1993. Ann Intern Med 124:407-413.

150. Kizner CH, Yousem SA (1988) Systemic light chain deposition disease presenting as multiple pulmonary nodules. Am J Surg Pathol 12:405-413.

151. Askin FB (1990) Pulmonary disorders in the collagen vascular diseases. Human Pathol 21:465-466.

152. Wiedeman HP, Matthay RA (1989) Pulmonary manifestations of the collagen vascular diseases. Clin Chest Med 10:677-721.

153. Faurschou P, Francis D, Fuarup P (1985) Thoracoscopic, histological and clinical findings in nine cases of rheumatoid pleural effusion. Thorax 40:371-375.

154. Anaya JM, Diethelm L, Ortiz AC et al. (1995) Pulmonary involvement in rheumatoid arthritis. Semin Arthritis Rheum 25:242-254.

155. Shadick NA, Fanta $\mathrm{CH}$, Weinblatt ME et al. (1994) Bronchiectasis a late feature of severe rheumatoid arthritis. Medicine 73:161-170.

156. Geddes DM, Corrin B, Brewerton DA et al. (1977) Progressive airway obliteration in adults and its association with rheumatoid disease. Quart J Med 46:427-444

157. Hakala M, Paakko P, Huhti E et al. (1990) Open lung biopsy of patients with rheumatoid arthritis. Clin Rheumatol 9:452-460.

158. Segal AM, Calabrese LN, Ahmad M et al. (1985) The pulmonary manifestations of systemic lupus erythematosus. Semin Arthritis Rheum 14:202-224.

159. Churg A, Franklin W, Chan KL et al. (1980) 
Pulmonary hemorrhage and immune-complex deposition in the lung. Arch Pathol Lab Med 104:388.

160. Eagan J, Memoli VA, Roberts SL et al. (1978) Pulmonary hemorrhage and systemic lupus erythematosus. Medicine 57:545-560.

161. Matthay RA, Schwartz MI, Petty TL et al. (1974) Pulmonary manifestations of systemic lupus erythematosus: review of twelve cases of acute lupus pneumonitis. Medicine 54:397-409.

162. Inoue $T$, Kanayama $Y$, Ohe $A$ et al. (1979) Immunopathologic studies of pneumonitis in systemic lupus erythematosus. Ann Intern Med 91:30-34.

163. Nair SS, Askari AD, Popelka CG et al. (1980) Pulmonary hypertension and systemic lupus erythematosis. Arch Intern Med 140:109.

164. McCarthy DS, Baragar FD, Dhingra S et al. (1988) The lungs in systemic sclerosis (scleroderma): a review and new information. Semin Arthritis Rheum 17:271-283.

165. Papiris SA, Vlachoyiannopoulos PG, Maniati MA et al. (1997) Idiopathic pulmonary fibrosis and pulmonary fibrosis in diffuse systemic sclerosis: two fibroses with different prognoses. Respiration 64:81-85.

166. Yousem SA (1990) The pulmonary pathologic manifestations of the CREST Syndrome. Human Pathol 21:467-474.

167. Ungerer RG, Tashkin DP, Fust D et al. (1983) Prevalence and clinical correlates of pulmonary arterial hypertension in progressive systemic sclerosis. Am J Med 75:65-74.

168. Tazelaar HD, Viggiano RW, Pickersgill $\mathrm{J}$ et al. (1990) Interstitial lung disease in polymyositis and dermatomyositis. Am Rev Respir Dis 141:727-733.

169. Strimlan CV, Rosenow EC, Divertie MD et al. (1976) Pulmonary manifestations of Sjögren's syndrome. Chest 70:354.

170. Deheinzelin D, Capelozzi VL, Kairalla RA et al. (1996) Interstitial lung disease in primary Sjögren's syndrome. Clinical-pathological evaluation and response to treatment. Am J Respir Crit Care Med 154:794-799.

171. McCurley TL, Collins RD, Ball E et al. (1990) Nodal and extranodal lymphoproliferative disorders in Sjögren's syndrome: a clinical and immunopathologic study. Human Pathol 21:482-492.

172. Hansen LA, Prakosh BS, Colby TV (1989) Pulmonary lymphoma in Sjögren's syndrome. Mayo Clin Proc 64:920-931.

173. Rosenow E, Myers J, Swenson S et al. (1992) Druginduced pulmonary disease. An update. Chest 102:239-250.

174. Myers JL (1993) Diagnosis of drug reactions in the lung. In: Churg A, Katzenstein A, eds. The lung. Current concepts. Baltimore, Williams and Wilkins, pp. 32-53.

175. Heard BE, Cooke RA (1968) Busulfan lung. Thorax 23:187-193.

176. O'Driscoll BR, Hasleton PS, Taylor PM et al. (1990) Active lung fibrosis up to 17 years after chemother- apy with carmustine (BCNU) in childhood. N Engl J Med 323:378-382.

177. Barrera P (1994) Methotrexate-related pulmonary complications in patients with rheumatoid arthritis. Am Rheum Dis 53:434-439.

178. Martin WJ, Rosenow EC (1988) Amiodarone pulmonary toxicity. Recognition and pathogenesis. Chest 93:1067-1075, 1242-1246.

179. Movsas B, Raffin TA, Epstein AH et al. (1997) Pulmonary radiation injury. Chest 111:1061-1075.

180. Warren S, Spencer J (1940) Radiation reaction in the lung. Am J Roentgenol 43:692-701.

181. Jennings FL, Arden A (1962) Development of radiation pneumonitis: time and dose factors. Arch Path 74:351-360.

182. Boyle JY, Nesme P, Bejui-Thivolet F et al. (1995) Migratory organizing pneumonitis 'primed' by radiation therapy. Eur Respir J 8:322-326.

183. Crestani B, Kambouchner M, Soler P et al. (1995) Migratory bronchiolitis obliterans organizing pneumonia after unilateral radiation therapy breast carcinoma. Eur Respir J 8:318-321.

184. Roberts CM, Foulcher E, Zaunders JJ et al. (1993) Radiation pneumonitis: A possible lymphocytemediated hypersensitivity reaction. Ann Intern Med 118:696-700.

185. Morgan GW, Breit SN (1995) Radiation and the lung: A reevaluation of the mechanisms pulmonary injury. Int J Radiat Oncol Biol Physics 31:361-369.

186. Craighead JE, ed. (1995) Pathology of environmental and occupational disease. Moseby-Yearbook, St Louis.

187. Churg A, Green FY (1988) Pathology of occupational lung disease. Igaku-Shoin, New York.

188. Green FY, Laqueur WA (1980) Coalworkers pneumoconiosis. Pathol Annu 15 (pt 2):333-410.

189. Davis JMG, Chapman J, Collings P et al. (1983) Variation in the histological patterns of the lesions of coal workers pneumoconiosis in Britain and their relationship to lung dust content. Am Rev Respir Dis 128:118-124.

190. Craighead JE, Kleinerman J, Abraham J et al. (1988) Diseases associated with exposure to silica and nonfibrous silicate minerals. Arch Pathol Lab Med 112:673-720.

191. Cowie RL, Hay M, Thomas RG (1993) Association of silicosis, lung dysfunction and emphysema in gold miners. Thorax 48:746-749.

192. Ng TP, Chan SL (1991) Factors associated with massive fibrosis in silicosis. Thorax 46:229-232.

193. Craighead JE, Abraham J, Churg A et al. (1982) The pathology of asbestos associated diseases of the lungs and pleural cavities: Diagnostic criteria and proposed grading schema. Arch Pathol Lab Med 106:544-596.

194. Mossman BT, Gee JBL (1989) Asbestos-related diseases. N Engl J Med 320:1721-1730.

195. Churg A, Wright JL (1983) Small airways disease and mineral dust exposure. Pathol Annu 18 (pt 2):233-251.

196. Wright JL, Churg A (1984) Morphology of small 
airway lesions in patients with asbestos exposure. Human Pathol 15:68-75.

197. Churg A (1993) Asbestos, asbestosis and lung cancer. Mod Pathol 6:509-510.

198. Roggli VL, Hammar SP, Pratt PC et al. (1994) Does asbestos or asbestosis cause carcinoma of the lung? Am J Indust Med 26:835-838.

199. Abraham JL (1994) Asbestos inhalation, not asbestosis causes lung cancer. Am J Indust Med 26:839-842.

200. Wilkinson P, Hansell DM, Janssens J et al. (1995) Is lung cancer associated with asbestos exposure when there are no small opacities on the chest radiograph? Lancet 345:1074-1078.

201. Freiman DG, Hardy HL (1970) Beryllium disease. The relationship of pulmonary pathology to course and prognosis based on a study of 130 cases from the US beryllium case registry. Human Pathol $1: 25-44$.

202. Kriebel D, Brain JD, Sprince NL et al. (1988) The pulmonary toxicity of beryllium. Am Rev Respir Dis 137:464-473.

203. Cugell DW (1992) The hard metal diseases. Clin Chest Med 13:269-279.

204. Davison AG, Haslam PL, Corrin B et al. (1983) Interstitial lung disease and asthma in hard-metal workers: bronchoalveolar lavage, ultrastructural, and analytical findings and results of bronchial provocation tests. Thorax 38:119-128.

205. Demedts M, Gheysens B, Nagels J et al. (1984) Cobalt lung in diamond polishers. Am Rev Respir Dis 130:130-135.

206. Gheysen B, Auwerx J, Van den Eekhout A (1985) Cobalt-induced bronchial asthma in diamond polishers. Chest 88:740-744.

207. Wright-Brown V, McClain KL, Talpaz M et al. (1997) Physiology and pathophysiology of dendritic cells. Human Pathol 28:563-579.

208. Soler P, Moreau A, Basset et al. (1989) Cigarette smoking induced changes in the number and differentiated state of pulmonary dendritic cells/ Langerhans cells. Am Rev Respir Dis 139:1112-1117.

209. Egeler RM, Angio GJ (1995) Langerhans cell histiocytosis. J Pediat 127:1-11.

210. Basset F, Corrin B, Spencer H et al. (1978) Pulmonary histiocytosis $\mathrm{x}$. Am Rev Respir Dis 118:811-20.

211. Yu RC, Chu C, Buluwela L et al. (1994) Clonal proliferation of Langerhans cells in Langerhans cell histiocytosis. Lancet 343:767-768.

212. Willman CL, Busque L, Griffith BB et al. (1994) Langerhans-cell histiocytosis (histiocytosis- $x$ ) a clonal proliferative disease. $\mathrm{N}$ Engl J Med 331:154-160.

213. Soler P, Kambouchner M, Valeyre D et al. (1992) Pulmonary Langerhans cell granulomatosis (histiocytosis-x). Annu Rev Med 43:105-115.

214. Auld D (1957) Pathology of eosinophilic granuloma of the lung. Arch Pathol 63:113-131.

215. Travis WD, Borok Z, Roum JH et al. (1993) Pulmonary Langerhans cell granulomatosis (histio- cytosis-x). A clinicopathologic study of 48 cases. Am J Surg Pathol 17:971-986.

216. Corrin B, Liebow AA, Friedman PJ (1975) Pulmonary lymphangiomyomatosis. A review. Am J Pathol 79:347.

217. Carrington CB, Cugell DW, Gaensler EA et al. (1977) Lymphangiomyomatosis. Physiologic pathologic-radiologic correlations. Am Rev Respir Dis 116:977-995.

218. Bonetti F, Chiodera PL, Pea M et al. (1995) Transbronchial biopsy in lymphangiomyomatosis of the lung. HMB 45 for diagnosis. Am J Surg Pathol 17:1092-1102.

219. Templeton PA, McLoud TC, Muller NL et al. (1989) Pulmonary lymphangioleiomyomatosis: CT and pathologic findings. J Comput Assist Tomogr 13:54-57.

220. Taylor JR, Ryu J, Colby TV et al. (1990) Lymphangiomyomatosis. Clinical course in 32 patients. N Eng J Med 323:1254-1260.

221. O'Brien JD, Lium JH (1995) Lymphangioleiomyomatosis recurrence in the allograft after simple lung transplantation. Am J Resp Crit Care Med 151:2033-2036.

222. Yousem SA, Colby TV, Carrington CB (1985) Follicular bronchitis/bronchiolitis. Human Pathol 16:700-706.

223. Kradin R, Mark E (1985) Benign lymphoid disorders of the lung with a theory regarding their development. Human Pathol 14:857-867.

224. Koss M, Hochholzer L, Nichols P et al. (1983) Primary non-Hodgkin's lymphoma and pseudolymphoma of the lung. A study of 61 patients. Human Pathol 14:1024-1038.

225. Thompson GP, Utz JP, Rosenow EC et al. (1993) Pulmonary lymphoproliferative disorders. Mayo Clin Proc 68:804-817.

226. Travis WD, Fox $\mathrm{CH}$, Devaney KO et al. (1992) Lymphoid pneumonitis in 50 adult patients infected with the human immunodeficiency virus: lymphocytic interstitial pneumonitis versus nonspecific interstitial pneumonitis. Human Pathol 23:529-541.

227. Oldham SAA, Castillo M, Jacobson FL et al. (1989) HIV-associated lymphocytic interstitial pneumonia: radiologic manifestations and pathologic correlation. Radiology 170:83-87.

228. Itescu S, Brancato LJ, Buxbaum J et al. (1990) A diffuse infiltrative CD8 lymphocytosis syndrome in human immunodeficiency virus (HIV) infection: a host immune response associated with HLA DR5. Ann Intern Med 112:3-10.

229. Kaan PM, Hegele RG, Hayashi S et al. (1997) Expression of bcl-2 and Esptein-Barr virus LMP1 in lymphocytic interstitial pneumonia. Thorax 52:12-16.

230. Li G, Hansmann NL, Zwinger $\mathrm{T}$ et al. (1990) Primary lymphomas of the lung: morphological, immunohistochemical and clinical features. Histopathol 16:519-531.

231. Fiche M, Capron F, Berger F et al. (1995) Primary pulmonary non-Hodgkin's lymphomas. Histopathology 26:529-537. 
232. Myers JL (1990) Lymphomatoid granulomatosis: past, present, ... future? Mayo Clin Proc 65:274-278.

233. Guinee D, Jaffe E, Kingman D et al. (1994) Lymphomatoid granulomatosis. Evidence for a proliferation of Epstein-Barr virus-infected B lymphocytes with a prominent $\mathrm{T}$ cell component and vasculitis. Am J Surg Pathol 18:753-764.

234. Dail DH, Liebow AA, Gmelich JT et al. (1983) Intravascular, bronchiolar and alveolar tumor of the lung (IVBAT). An analysis of twenty cases of a peculiar sclerosing endothelial tumor. Cancer 51:452-464.

235. Clayton FC (1988) The spectrum and significance of bronchioloalveolar carcinoma. Pathol Annu 23:361-394.
236. Barkley JE, Green MR (1996) Bronchioloalveolar carcinoma. J Clin Oncol 14:2377-2386.

237. Aguayo SM, Miller YE, Waldron JA et al. (1992) Idiopathic diffuse hyperplasia of pulmonary neuroendocrine cells and airways disease. $\mathrm{N}$ Engl J Med 327:1285-1298.

238. Sheerin N, Harrison NK, Sheppard MN et al. (1995) Obliterative bronchiolitis caused by multiple tumorlets and microcarcinoids successfully treated by single lung transplantation. Thorax 50:207-209.

239. Stein MG, Mayo J, Muller N et al. (1987) Pulmonary lymphangiitic spread of carcinoma: appearance on CT scans. Radiol 162:371-375. 